\title{
Las enfermedades ison solo padecimientos?: biomedicina, formas de atención "paralelas" y proyectos de poder
}

\author{
Is disease merely illness? Biomedicine, "parallel" \\ forms of care and power
}

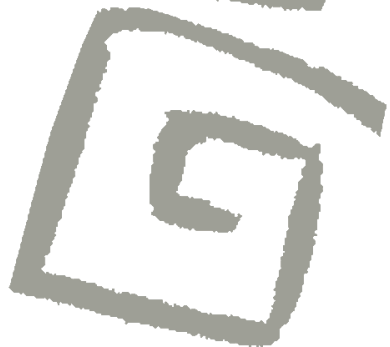

Menéndez, Eduardo L.'

${ }^{1}$ Doctor en Ciencias Antropológicas. Profesor e investigador, Centro de Investigaciones $y$ Estudios Superiores en Antropología Social (CIESAS) México. Coordinador del Seminario Permanente de Antropología Médica (SPAM) emenendez1@yahoo.com.mx
RESUMEN Partiendo de la propuesta de Giovanni Berlinguer, de que los procesos de salud/enfermedad constituyen algunos de los principales espías de las contradicciones de un sistema, se describen en primer lugar algunos casos ocurridos en contextos capitalistas centrales y periféricos, así como en Estados denominados "socialistas reales", que permiten observar dicho papel. En segundo lugar, observamos los procesos y sobre todo las interpretaciones que se han desarrollado en América Latina y especialmente en México respecto del papel atribuido a la medicina tradicional en la identidad y pertenencia de los pueblos originarios, y que subrayan la incompatibilidad de las cosmovisiones indígenas con la biomedicina, analizando algunos proyectos que se impulsaron en términos de salud intercultural, y que concluyeron en su mayoría en fracasos, tanto desde el punto de vista de la salud, como político. Se subraya el contenido y la perspectiva casi exclusivamente ideológicos de dichos proyectos, y su poca relación con la realidad de los pueblos originarios. Por último, se trata de ver si la trayectoria de estas concepciones y programas de salud expresan y explican el notable repliegue que sufren desde hace casi diez años la mayoría de los movimientos étnicos en América Latina.

PALABRAS CLAVES Medicina Tradicional; Organizaciones Indígenas; México.

ABSTRACT Following Giovanni Berlinguer's proposal that health/disease processes are one of the primary spies into the contradictions of a system, this article describes cases that occurred in central and peripheral capitalist contexts as well as in the socalled "real socialist" States that allow such a role to be seen. Secondly, we observe the processes and above all the interpretations developed in Latin America and especially Mexico regarding the role attributed to traditional medicine in the identity and sense of belonging of indigenous peoples, which emphasize the incompatibility of indigenous worldviews with biomedicine. To do so we analyze projects that were carried out under the notion of intercultural health, which in large part resulted in failure both in health and political terms. The almost entirely ideological content and perspective of these projects is highlighted, as is the scant relationship they hold with the reality of indigenous people. Lastly, the impact and role that the advance of these conceptualizations and health programs might have had in the disengagement experienced over the last nearly ten years in the ethnic movements of Latin America is considered.

KEY WORDS Medicine, Traditional; Indigenous Organizations; Mexico. 
Para Juan Luis Sariego

Desde hace años considero que, a través de los procesos de salud/enfermedad/atenciónprevención (s/e/a-p), pueden ser observados y analizados gran parte de los problemas económico-políticos e ideológico-culturales con mayor transparencia y menores sesgos que si los estudiáramos en términos específicos. Incluso podemos llegar a detectar conflictos y hasta contradicciones, así como formular nuevos interrogantes, generando lecturas diferentes o al menos complementarias de las desarrolladas por los especialistas -por ejemplo- en movimientos sociales, en identidades étnicas o en relaciones de género.

A finales de la década de 1960, Giovanni Berlinguer $(1,2)$ propuso que los procesos de saludenfermedad constituían algunos de los principales "espías" de las contradicciones de un sistema; es decir que a través de estos se expresan los conflictos y las contradicciones más allá de las interpretaciones, ocultamientos o racionalizaciones que los gobiernos, los medios y los intelectuales orgánicos y no orgánicos suelen generar. Pero estos conflictos y contradicciones no solo refieren a los países capitalistas centrales, sino que a través de los procesos de s/e/a-p también los podemos observar en los países capitalistas periféricos, en los socialistas "reales" y "de mercado", y en las sociedades precapitalistas, incluidas sus continuidades actuales. Más aún, pueden expresar los sesgos, contradicciones e imaginarios de los analistas, así como contribuir a problematizar la realidad.

Es decir, necesitamos acercarnos a la realidad no solo desde lo manifiesto, evidente y explicitado, sino desde los aspectos marginados, secundarios e incluso irrelevantes; tan irrelevantes que no se "ven", como por ejemplo ocurre con el racismo que caracteriza a nuestras sociedades latinoamericanas, pero que es negado a nivel tanto de las políticas públicas como de los estudios académicos, aunque emerge en nuestra vida cotidiana, y es paradojalmente evidenciado en forma permanente por los medios de comunicación masiva, en gran parte de nuestros países. Y por eso necesitamos observar las contradicciones y conflictos a través de lo obvio, de lo que vemos pero no miramos, y frecuentemente no reflexionamos (3-5).

La propuesta de Berlinguer, que ha sido escasamente desarrollada por la Medicina Social y por la Antropología Médica de Latinoamérica, podemos observarla a través de una variedad de casos correspondientes a diferentes situaciones y momentos históricos, de los cuales solo mencionaré algunos. Durante la década de 1960 se "descubrió" que EE.UU. tenía la tasa de mortalidad infantil más alta entre los países capitalistas desarrollados, e incluso más alta que países como Cuba, lo cual condujo a reconocer la existencia de amplios bolsones de pobreza, así como la relación de estos con la mortalidad infantil, con la desnutrición, con graves problemas de salud mental, así como con el racismo en el país que lideraba el desarrollo capitalista a nivel mundial (6-8).

En la misma década, los datos epidemiológicos referidos a mortalidad general e infantil y a desnutrición evidenciaron un fuerte deterioro económico y de salud en las zonas musulmanas del sur de la URSS, vaticinando la emergencia de fuertes conflictos políticos y étnicos, que ulteriormente se dieron. El descenso de la natalidad y el incremento de la mortalidad que afectaron a la URSS desde finales de la década de 1970 hasta la actualidad, a fines de los años ochenta se transformaron en un derrumbe demográfico que implicó que la esperanza de vida disminuyera en alrededor de once años; lo cual constituyó no solo una catástrofe social que afectó especialmente a los varones rusos, sino que evidenció el colapso social e ideológico que estaba ocurriendo en la Federación Rusa, que estaba dejando de ser "soviética" $(9,10)$. Este colapso, que no tiene parangón con ningún otro proceso similar, y que ocurrió en la que había sido la segunda potencia mundial en términos políticos y militares, ha sido escasamente asumido por los que estudiamos los procesos de s/e/a-p, así como también lo que significó en términos de identidad nacional y en cierta medida ideológica a nivel de los sujetos, y sobre todo de los varones que en pocos años redujeron tan fuertemente sus esperanzas de vida. Las caídas o fracturas de las "cosmovisiones" no solo se dan a nivel de los grupos étnicos, sino que las caídas o fracturas de las ideologías colectivas convertidas en gran medida en "cultura" se dan también en las sociedades denominadas "complejas".

El incremento constante de las altas tasas de suicidio que se registraron en Hungría a partir del inicio de la década de 1950 y, en Cuba, a partir de finales de la misma década, especialmente en 
jóvenes, evidenció que algo estaba pasando con el "nuevo hombre" y, en general, con los desarrollos sociales e ideológicos de los "socialismos reales" (11-14). A su vez, la emergencia y expansión del VIH-sida desde principios de la década de 1980 evidenció y sigue evidenciando el notable bisexualismo del varón en muchas sociedades y, en particular, en las latinoamericanas, lo cual se expresó especialmente a través del incremento del VIH-sida en mujeres transmitido por su pareja masculina.

Toda una serie de datos epidemiológicos constituyen expresiones de la situación de inferioridad y marginalidad social y económica en que han vivido y viven las mujeres en la casi totalidad de las sociedades, y que se pone de manifiesto tanto en las tasas de mortalidad materna y en los tipos de suicidio a que fueron y son inducidas cultural y socialmente las mujeres en India y en China, como en la menor esperanza de vida que han tenido sobre todo en las sociedades campesinas, hasta fechas relativamente recientes. En la casi totalidad de las sociedades, incluida la capitalista, el estatus de la mujer no solo fue siempre inferior al del varón, sino que con la mujer se podía hacer casi cualquier cosa, incluso lapidarla, incinerarla en vida o violarla, lo cual estaba y sigue siendo legalizado por los usos y costumbres en numerosas sociedades actuales. Será en las sociedades capitalistas en las que la mujer, sobre todo desde el último tercio del siglo $X X$, además de tener una esperanza de vida mayor que el varón, alcance las mayores expectativas de vida conocidas hasta la actualidad en cualquier sociedad. Será en estas sociedades donde la mujer acceda al mayor empoderamiento comparado con cualquier otro sistema, y contrastando con la situación de inferioridad de las mujeres en la mayoría de las sociedades de las cuales tenemos información.

Si algo expresa la mercantilización de casi todo por el capitalismo es el desarrollo actual de la biomedicina, que en forma directa e indirecta ha convertido en mercancía todo producto y acción biomédico, inventando incluso padecimientos, o impulsando el uso de medicamentos casi sin control, o con controles permisivos. Más aún, mercantilizando la vida desde el nacimiento a través del notable incremento de los partos por cesárea, o prolongando una muerte hasta que el sujeto y/o su seguro médico aguanten (15-17).
Desde hace años sabemos que la denominada "guerra contra las drogas" no solo ha fracasado, pues siguen incrementándose los consumos de sustancias consideradas "adictivas" así como el narcotráfico, sino que los expertos no pueden explicar en términos biomédicos por qué varias de las principales sustancias "adictivas" son legales mientras otras, de consecuencias mucho menores, son tratadas como "ilegales". Tanto los criterios de legalidad e ilegalidad, como los de "adicción" o "dependencia" no resisten la menor indagación y reflexión, ni en términos técnicos, ni de sentido común. Lo evidente desde hace varios años es que la "guerra a las drogas" ha tenido y sigue teniendo funciones de control social, político e ideológico, y tiene que ver muy poco con la salud de los ciudadanos en general y, sobre todo, de los considerados "adictos" (18-22).

Una parte de los críticos al capitalismo parece añorar cada vez más a las sociedades pre o no capitalistas por varias razones y, especialmente, por la relación con "la tierra" que habrían desarrollado dichas sociedades, dado que tendrían un trato sagrado y conservacionista. Más allá de que esta actitud sea o no cierta, necesitamos recordar que en las sociedades precapitalistas así como en las capitalistas, hasta por lo menos mediados del siglo XIX, la esperanza de vida era muy baja, es decir, estaba entre 20 y 30 años de edad o aún menos, debido a varios factores, siendo uno de los más determinantes la mortalidad por enfermedades infectocontagiosas. Pero además, muchas de nuestras sociedades precapitalistas -lo cual ha podido registrarse etnográficamente- aplicaron criterios "eugenésicos" a través de rituales sociales, como fue el asesinato de gemelos y otras prácticas de infanticidio referidas en ciertos casos a niños que nacían con malformaciones, o con aspectos considerados malformaciones. Las tasas de mortalidad general, infantil, en menores de cinco años pero también en jóvenes y adultos, Ilegaron en esas sociedades a niveles que actualmente no podemos ni pensar $(23,24)$.

Ahora bien, subrayo que los procesos de s/e/a-p evidencian los problemas señalados tanto a nivel de los países capitalistas centrales como de los periféricos, en forma constante, y de allí la posibilidad de seguir registrándolos y de proponer interpretaciones que, a partir de los procesos de s/e/a-p, no solo refieran a procesos económico- 
políticos e ideológico-culturales, sino que encuentren en su modificación la solución o por lo menos la limitación de determinados daños a la salud. Y así, por ejemplo, observamos que desde mediados de la década de 1990, en Gran Bretaña se incrementa constantemente el número de niños con raquitismo, un padecimiento que fue endémico en los niños de clase baja urbana durante gran parte del periodo victoriano y que en su momento sintetizó las denuncias respecto del tipo de sociedad capitalista impulsada por quien era entonces el país dominante a nivel mundial. Entre 1995 y 2011 el número de niños hospitalizados por raquitismo se cuadriplicó en Gran Bretaña, coincidiendo con el incremento de las desigualdades socioeconómicas generadas por el neoliberalismo.

La epidemia de Ébola surgida y expandida en 2014 -principalmente en tres de los países más pobres de África (Guinea, Sierra Leona y Liberia)evidenció múltiples procesos, pero especialmente dos. Por una parte, las consecuencias de la aplicación de las políticas económicas del Fondo Monetario Internacional (FMI), sobre todo en Guinea y Sierra Leona, ya que dichas políticas implicaron una fuerte reducción de gastos del sector público que afectó, en particular, al sector salud. Dichos países se vieron obligados a derivar sus ingresos al pago de las deudas contraídas con las fuentes de financiamiento, en lugar de dedicarlos a programas de salud, lo cual acentuó las consecuencias negativas generadas por la descentralización de los servicios de salud, impuesta también por el FMI. Más aún, estas políticas implicaron el despido masivo de trabajadores de la salud en dichos países, de tal manera que, por ejemplo, en Sierra Leona el personal de salud pasó de una relación de 0,11 por cada 1.000 habitantes en 2004 a 0,02 en 2008, todo lo cual debe ser asociado con la expansión de las empresas extractivas, la situación económico/política de dichos países caracterizados por guerras civiles, y el enriquecimiento de los sectores gobernantes a través de mecanismos de corrupción normalizados (25).

En segundo lugar, la epidemia de Ébola evidenció la escasa, tardía y lenta reacción de la ayuda internacional respecto de una enfermedad que generaba miles de muertos, y que pudo haber sido tempranamente controlada con el uso de los recursos técnicos que poseen, principalmente, los países de mayor desarrollo. Según el presidente de Médicos Sin Frontera (MSF) de España: "Si el mundo hubiera respondido con contundencia desde el principio, hubiésemos frenado el brote hace ya meses" (26). Pero esta ayuda fue mínima por parte de los países con mayor capacidad tecnológica y financiera, sobre todo, cuando se verificó que la epidemia no se expandía a nivel mundial y no afectaba a los países centrales. Si bien el FMI negó estas acusaciones, aduciendo además que entregó a dichos países financiamientos extraordinarios para enfrentar la epidemia, dicho financiamiento no solo fue tardío sino que no compensó las consecuencias de la aplicación de las políticas neoliberales impuestas por el FMI.

Los procesos de s/e/a-p enumerados posibilitan, por lo tanto, detectar, describir y analizar en diferentes contextos económico-políticos y socioculturales tanto las contradicciones y conflictos como los objetivos reales y las reacciones de los sectores sociales dominantes y también de los dominados, así como muchos de nuestros mitos e imaginarios colectivos, incluidos los académicos. Es decir, nos posibilita analizar las Ilamadas narrativas, no solo para estudiar sus significados en sí, sino para ver qué tienen que ver con los hechos y procesos, y lo que ideológicamente expresan, así como, obviamente, nos indican la necesidad de cambiar las políticas económicas y sociales que generan gran parte de las situaciones señaladas.

De allí que el objetivo central de este texto es observar si a través de lo ocurrido durante las décadas de 1980, 1990 y la primera del siglo XXI, con los procesos y actores sociales organizados en torno a la denominada medicina tradicional, pueden explicarse por lo menos algunos aspectos relevantes de la trayectoria, repliegue y estancamiento de los movimientos étnicos en México.

\section{PERTENENCIAS, IDENTIDADES Y NEGACIONES}

Es a partir de lo señalado que presentaré interrogantes respecto de procesos que implican aspectos económico-políticos y socioculturales, que han sido abundantemente tratados y debatidos, en especial, desde la década de 1970 hasta la actualidad, y que tienen que ver con los movimientos 
indígenas y sus objetivos de rehabilitación cultural y empoderamiento político, los que se constituyen en una posible alternativa a las sociedades capitalistas, a partir de las formas de vida y de las cosmovisiones desarrolladas y usadas por dichos grupos. Y trataremos de observarlo a través de los procesos de s/e/a-p, por dos razones básicas: porque es a través de estos que, según analistas que citaremos más adelante, no solo se expresan sino que "se conservan" más los aspectos centrales de las cosmovisiones de los pueblos originarios comparados con cualquier otro tipo de procesos. Así como, por el papel metodológico y problematizador que, como ya señalamos, pueden cumplir.

Desde finales de la década de 1960 se desarrollaron diferentes concepciones sobre las principales características de los movimientos indígenas que se organizaron y tuvieron una fuerte presencia en ciertos países de América Latina durante las décadas de 1970, 1980 y 1990, lo cual -y lo subrayo- no niega la existencia previa de organizaciones y movilizaciones indígenas sino que, sobre todo, durante las décadas mencionadas, estas fueron mucho más numerosas y desarroIlaron nuevos objetivos y estrategias (27). Algunos de los procesos que más se discutieron fueron los que tenían y tienen que ver con las identidades, cosmovisiones y pertenencias étnicas, en función de los objetivos señalados, y que dieron lugar al surgimiento de varias orientaciones que sintetizaremos esquemáticamente en dos: una, que plantea la existencia de una identidad, pertenencia y cosmovisión indígena monolítica, de carácter fundamentalmente precolombino, que sostiene que si bien existen procesos de cambio y aculturación, estos no afectan los núcleos identitarios, sino que sigue dominando una cosmovisión diferencial respecto de la sociedad occidental, a la cual también suelen considerar como unificada y monolítica, sobre todo, en términos culturales. $Y$ otra, que asume la existencia de cambios constantes, especialmente de tipo económico-políticos, impulsados por la expansión de la sociedad dominante, y que si bien reconoce modificaciones, incluso sustantivas, considera que los grupos étnicos realizan un proceso de apropiación, que convierte en propios aspectos generados en otras culturas y sociedades, de tal manera que siguen manteniendo una identidad y cosmovisión diferencial aunque modificada.
Ahora bien, respecto de estas dos posiciones, necesitamos aclarar varias apreciaciones, comenzando por tratar de entender ¿en qué consisten actualmente -y subrayo lo de actualmente- la cultura llamada occidental así como la precolombina?, sobre todo cuando son pensadas en términos monolíticos y esencialistas. Así como también entender en qué consiste la "apropiación" para explicar, entre otras cuestiones, ¿por qué pese a los cambios generados, por ejemplo, en el perfil epidemiológico de la morbimortalidad o en el notorio descenso de las tasas de mortalidad general y etarias en la mayoría de los grupos étnicos, se mantienen la identidad y la cosmovisión étnica, dado que la enfermedad y la muerte, así como su tratamiento sociocultural y técnico, son parte central de casi toda cosmovisión?

Además, para precisar nuestros interrogantes tendríamos que analizar, entre otros, no solo los conceptos de identidad y cosmovisión, sino también los de actores sociales, persona y subjetividad que manejan dichas orientaciones; $y$ aclarar también, cuando hablamos de movimiento étnico o de medicina tradicional, si asumimos que existe una diversidad de movimientos étnicos y de medicinas tradicionales que pueden tener coincidencias, pero también fuertes diferencias entre sí (a). Pero ahora no me detendré en tratar estos aspectos, sino que, como propuse, formularé algunos interrogantes respecto de los procesos étnicos señalados para poder avanzar en su análisis. Y lo primero a preguntarnos es ¿cómo afecta la identidad, cosmovisión y pertenencia de los grupos étnicos de América Latina, y en particular de México, la constante expansión y penetración de la biomedicina? (b). Y cuando digo biomedicina me refiero tanto a la instalación de servicios biomédicos y a la aplicación de programas preventivos, como al uso de productos, prácticas y concepciones biomédicas en la vida cotidiana de nuestros grupos étnicos, más allá de que existan o no servicios biomédicos. La biomedicina no solo se ha expandido a través del sector salud, sino también a través del Instituto Lingüístico de Verano, de la enorme cantidad de organizaciones no gubernamentales (ONG), así como de las "misiones" protestantes que han trabajado sobre procesos de salud en comunidades mexicanas.

Una visión biomédica sumamente extendida, incluso entre científicos sociales, es la de pensar la 
influencia biomédica solo cuando existen servicios médicos oficiales o privados, y no cuando esta se expresa a través de la existencia de medicinas de patente en las tiendas de las comunidades, en el uso de fármacos por curadores tradicionales o en la colaboración de la población nativa -incluidos curadores tradicionales- para realizar vigilancia epidemiológica respecto del paludismo, la enfermedad de Chagas o la oncocercosis. Como lo he sostenido en varios trabajos, necesitamos asumir que la biomedicina es uno de los principales productores de ideología, de consenso y de hegemonía, y que estos se ejercen en la vida cotidiana y no solo a través de los servicios biomédicos. Por lo cual, pensar la biomedicina solo donde existen servicios de salud, evidencia su notable efecto ideológico $(3,4,13,19,28,29)$.

Todo indica que los miembros de gran parte de los grupos étnicos utilizan cada vez más la biomedicina; que dichos grupos solicitan la instalación de centros de salud y de hospitales de tipo biomédico en sus comunidades; que las poblaciones reconocen cada vez más que sus hijos se mueren de gastroenteritis y no de mal de ojo, o por lo menos de ambos padecimientos; que en las tiendas, incluso de las pequeñas comunidades, existen analgésicos y vitaminas. Más aún, una parte de las mujeres indígenas, cuando pueden, utilizan toallitas higiénicas durante sus periodos menstruales y pañales desechables para sus hijos pequeños. Del mismo modo, vemos que los grupos étnicos utilizan no solo prácticas sino concepciones biomédicas, articulándolas con sus propios saberes a través del continuo proceso de autoatención que caracteriza a los pequeños grupos. Y respecto de estos procesos, necesitamos observar si los sujetos y grupos que desarrollan una concepción biomedicalizada mantienen la que fundamenta la identidad y cosmovisión "tradicional" de los procesos, o generan representaciones y prácticas que articulan sus formas tradicionales y las biomédicas de una nueva manera.

$Y$ esto necesita ser investigado y no dar por sentada cada una de estas posibilidades según los presupuestos, orientaciones y objetivos de los estudiosos y/o de los líderes movimientistas. Dicha investigación debería realizarse sobre la vida cotidiana de los sujetos y grupos, incluyendo lo que surge de los curadores tradicionales y no tradicionales, pero no reduciendo los estudios exclusivamente a lo que narran los curadores tradicionales, y aún menos a los discursos de los líderes políticos movimientistas o no, o de los intelectuales más o menos orgánicos. No negamos la importancia de lo que nos informa una partera, un curador herbolario o un shamán, así como un médico o una enfermera, pero reducir solamente a estos la información sobre los procesos de s/e/a-p, como ocurre en la mayoría de los estudios sobre enfermedades tradicionales y no tradicionales en México -incluidos los míos- nos permite obtener el punto de vista de los curadores, pero no tener una visión holística de los procesos de s/e/a-p. Para ello necesitamos trabajar con la población y con los curadores tradicionales, alternativos y biomédicos pero, sobre todo, con los sujetos que enferman, con sus familiares, con sus vecinos (c) $y$, por supuesto, con las condiciones económicopolíticas y socioculturales que condicionan pero no determinan los procesos de s/e/a-p.

Reiteradamente me he preguntado si lo que actualmente saben, piensan, dicen y hacen los shamanes ¿corresponde o no a lo que la población indígena según género, edad, nivel educativo, experiencia migratoria, participación política, pertenencia religiosa y otras variables dice, sabe, piensa y sobre todo hace? Y esto me lo he preguntado respecto de poblaciones en las que observamos cada vez más bilingüismo, o de vastas zonas indígenas donde niños y jóvenes ya no hablan maya, como ocurre en Yucatán (México).

Considero que una parte de los curadores tradicionales y, sobre todo, los de tipo shamánico, expresan los saberes y valores tradicionales en términos de pautas ideales, pero que ya no corresponden, por lo menos parcialmente, a lo que viven sobre todo los niños y los adolescentes.

Uno de los investigadores que más conoce sobre medicina tradicional de los Altos de Chiapas, y que ha sido desde su creación asesor de la Organización de Médicos Indígenas del Estado de Chiapas (OMIECH), y me refiero al Dr. Rafael Alarcón, nos recuerda que los j'iloles (shamanes) se caracterizan por interpretar los sueños, pero que el contenido de los sueños está experimentando notables cambios principalmente en niños y jóvenes indígenas, ya que en sus sueños han comenzado a aparecer temas sobre violencias referidas al narcotráfico, artes marciales, materiales pornográficos, personajes como Rambo, que son 
observados en la televisión o en videos en sus comunidades, así como también son producto de sus experiencias migratorias laborales en Cancún, en varios estados del norte de México y de EE.UU. Si bien los j'iloles siguen interpretando los sueños, lo hacen a partir de ciertas concepciones y contextos que no corresponden a los que ahora sueñan los niños y jóvenes.

Según Alarcón, los propios curadores indígenas señalan que ya no todos sus hijos e hijas sueñan, así como también reconocen positivamente que algunos lo hacen, ya que soñar es parte del proceso de iniciación shamánica. Pero en muchas ocasiones no es que los jóvenes no sueñen, sino que

\footnotetext{
...no quieren contar su sueño a sus mayores debido a que esto implica un compromiso con su comunidad. Si narran sus sueños, ya no podrán abandonar la comunidad, pues el sueño indica que tienen un "mandato de los dioses" para permanecer en la comunidad y servirla. Y actualmente, la mayoría de los jóvenes tienden cada vez más a salir de sus comunidades. [Estos procesos son los que] están conduciendo a que los j'iloles desaparezcan lentamente, y por eso el último video que elaboró el compañero Agripino del área de comunicación de la OMIECH lo titulamos "Los últimos j'iloles mayas". (d) (36)
}

Pero además, por lo menos respecto de los procesos de s/e/a-p, una parte de los analistas buscan casi exclusivamente las formas tradicionales de actuar como si estas no se modificaran, manejando nociones explícitas o implícitas de control sociocultural ajenas a las dinámicas actuales de la mayoría de los grupos étnicos (28). Si bien la Iglesia católica prohíbe el aborto, el suicidio -incluida la eutanasia-, el adulterio, el homicidio y muchos otros actos sociales convirtiéndolos en pecados mortales, una parte de los católicos -en algunos contextos, la mayoría- realizan estos actos pese a caer en pecado mortal, lo que evidencia no solo que hay diferentes maneras de ser católico, sino que casi siempre hay diferencias entre las representaciones y las prácticas sociales. Y procesos similares se dan por lo menos en los sujetos que adhieren al catolicismo dentro de los grupos étnicos, de tal manera que se están desarrollando diferentes maneras de ser indígena, asumiendo además que este proceso se viene dando en forma constante en los pueblos originarios, lo que podemos detectar sobre todo en las prácticas cotidianas de los sujetos y grupos étnicos.

Por lo tanto, es en lo que dicen y, sobre todo, en lo que hacen los distintos $-y$ subrayo lo de distintos- sujetos y grupos sociales, donde necesitamos observar los usos, los desusos, las resistencias, las aculturaciones, las autonomías, la creatividad que los sujetos y grupos desarrollan más allá de los discursos académicos y/o políticos que proponen la impugnación y negación de lo "occidental", o que validan positiva y unilateralmente las aculturaciones. Los procesos de lucha o de resistencia, así como los procesos de apropiación y los de hegemonía/subalternidad, debemos registrarlos en los quehaceres cotidianos de las personas y grupos. Y si bien no cabe duda de que procesos macrosociales como los de los medios de comunicación masiva influyen, considero que su influencia depende de cómo se procese la información a nivel local y microsocial. Y no debemos olvidar que los saberes biomédicos operan tanto a nivel macro como microsocial.

Como sabemos, México se ha convertido en el principal consumidor mundial de refrescos y en uno de los más importantes consumidores de alimentos chatarra (o basura), incluso en sus zonas indígenas; y la diabetes mellitus tipo 2 se va constituyendo a nivel nacional y de nuestros grupos étnicos en una de las principales causas de mortalidad y morbilidad. Es decir que nuestros grupos indígenas han sido penetrados no solo por bebidas y alimentos "occidentales" (e), no solo por enfermedades generadas por el consumo de dichos productos occidentales, sino también por la biomedicina occidental.

$Y$ es seguro que el consumo de refrescos tiene que ver, en gran medida, con los medios de comunicación masiva, las políticas de mercadeo locales, los procesos de urbanización y de migración, y con el turismo local (f). Pero además, ocurre que el enfrentamiento a la diabetes mellitus evidencia la ineficacia de la medicina tradicional y de sus operadores, así como crea expectativas en lo que puede hacer la biomedicina. Expectativas desarrolladas a través de su papel en el descenso de las tasas de mortalidad sobre todo infantil y 
de niños menores de cinco años, así como en la disminución de la mortalidad por enfermedades infectocontagiosas, lo cual es reconocido por los propios grupos étnicos. Por lo tanto, el papel y penetración de la biomedicina no se hace a través de aspectos triviales y secundarios, sino relacionado con las muertes "evitables", y además operando en forma directa e indirecta a nivel local (g).

Ahora bien, la expansión biomédica implica la existencia de oposiciones y rechazos, por varias razones, incluyendo el papel ambivalente de los productos y acciones biomédicas, ya que simultáneamente pueden enfermar pero también curar o por lo menos limitar el daño.

Necesitamos reconocer que más allá de estos aspectos, ocurre que en gran parte de los grupos étnicos americanos, la penetración occidental tiene varios siglos de antigüedad, dado que, por ejemplo, los aguardientes son productos occidentales que fueron apropiados hasta convertirse en imprescindibles en el desarrollo de los principales rituales sociales -incluidos rituales de sanaciónde gran parte de los pueblos originarios americanos. Pero además, desde hace pocos años, en algunos contextos étnicos, los aguardientes han sido reemplazados en los rituales por refrescos y, especialmente, por Coca-Cola (43). Y como también sabemos, la mayoría de las enfermedades infectocontagiosas que padecieron y padecen los grupos étnicos fueron importadas de occidente desde finales del siglo XV. Más aún, estas enfermedades diezmaron a la población amerindia, generando una de las catástrofes demográficas más profundas de las que tengamos información a nivel mundial; catástrofe frente a la cual los saberes indígenas evidenciaron una total impotencia, al igual que la medicina de los colonizadores. Pero con una diferencia radical: la población europea moría mucho menos debido a la creación de resistencias a dichas enfermedades, de las que carecía la población nativa. La catástrofe solo se dio en la población originaria, lo cual algo debió incidir en el desarrollo de relaciones de hegemonía/subalternidad generadas entre los colonizadores y las poblaciones nativas.

Ahora bien ¿cómo estos productos occidentales -desde el alcohol hasta las enfermedades infectocontagiosas y las resistencias diferenciales, así como la terrible y prolongada mortalidad ocurrida sobre todo durante los primeros siglos de la conquista- modificaron, o no, la cosmovisión e identidad de dichos grupos étnicos?, queda en el campo de las interpretaciones más o menos imaginarias, aun cuando podemos suponer que impactaron profundamente no solo en las cosmovisiones e identidades, sino también en las relaciones de hegemonía/subalternidad y de dominación. Pero, en términos comparados, actualmente estamos en condiciones de observar a nivel etnográfico si los refrescos, los productos chatarra, la diabetes mellitus tipo 2, pero también el $\mathrm{VIH}$-sida, la reducción de las mortalidades general y etarias, así como la desaparición o transformación de los curadores tradicionales y las representaciones y prácticas biomédicas modifican no solo los comportamientos sino también las cosmovisiones e identidades étnicas.

Por lo menos a nivel teórico, las enfermedades, especialmente las que generan altas tasas de mortalidad, los procesos de embarazo/parto/ puerperio, así como las técnicas del "cuerpo", o las acciones de sanación son parte básica de las cosmovisiones e identidades, pero me parece que la mayoría de los que estudiamos los procesos de s/e/a-p, de los que se preocupan por identidades y pertenencias étnicas en términos políticos e ideológicos, así como los que centran sus intereses en las cosmovisiones reducidas casi siempre a la dimensión religiosa, no estamos analizando estos aspectos, sino que a partir de nuestros objetivos y presupuestos hacemos interpretaciones periféricas y reducidas a nuestro campo de interés.

Lo señalado no ignora que existen estudios de notoria calidad entre nosotros $(36,44,45)$ que tratan esta problemática, y que en algunos casos subrayan el papel que la Iglesia católica y los diferentes credos protestantes tienen en la modificación de las cosmovisiones, pero sin observar el papel "religioso" (religación) que pueden tener la biomedicina y otras formas de atención de los padecimientos, máxime cuando estas iglesias no solo han cuestionado y hasta satanizado especialmente ciertos tipos de curadores y técnicas de sanación tradicionales, sino que han impulsado el reconocimiento y uso de la biomedicina. Por lo menos entre nosotros, las cosmovisiones se buscan casi exclusivamente en lo religioso; más aún cuando se incluyen los procesos de s/e/a-p es para observarlos desde la dimensión religiosa. 
Esta omisión o exclusión es aun más notable cuando documentamos que cada vez más niños indígenas nacen en clínicas y hospitales biomédicos, y se espera que esto ocurrirá con la totalidad de los futuros niños, por lo menos en México, generándose desde el nacimiento una impronta (imprinting) biomédica, que además excluye a las parteras "empíricas" del proceso de parto. Este proceso es impulsado por los gobiernos y en particular por el sector salud debido a la necesidad de reducir las muertes maternas y el embarazo infanto-juvenil, pero sobre todo para reducir la tasa de natalidad. Y es favorecido por la tendencia de los sujetos nativos a radicarse en medios urbanos, incluidas grandes urbes como la ciudad de México, donde se da la mayor concentración de población indígena del país.

Según Berrio, los datos de la Encuesta Nacional de la Dinámica Demográfica (46) indican que el $90 \%$ de las mujeres mexicanas habrían tenido el parto y el $97 \%$ habría tenido los controles natales en instituciones de salud. En su estudio de dos comunidades indígenas del estado de Guerrero, el $90 \%$ de las 100 mujeres encuestadas dijeron haber asistido a control durante su último embarazo, y el $60 \%$ lo hizo desde el primer trimestre. Más aún, encontró que el $80 \%$ de las mujeres de entre 15 y 24 años tuvieron el parto en hospitales de primer y segundo nivel mientras que, de las mujeres de entre 25 y 49 años, solo el 36\% lo tuvo en instituciones médicas. Incluso encontró que en las jóvenes indígenas no solo aparecen normalizados los análisis de laboratorio y ultrasonido, sino que manejan los conceptos de riesgo obstétrico y factores de riesgo. $\mathrm{Y}$ esto ocurre en el estado mexicano con mayor mortalidad materna $(47,48)$.

Si bien la atención biomédica del parto es todavía menor en la población indígena que en el resto de la población, el problema más fuerte no radica en el rechazo de la población originaria a la biomedicina, sino en la falta de cobertura de los servicios de salud debido a que una parte de la población indígena vive en localidades pequeñas y dispersas como ocurre, sobre todo, en el caso de Chiapas, donde el $80 \%$ de la población reside en comunidades de menos de 2.500 habitantes. Pero también se debe a la renuencia del personal de salud, y principalmente de los médicos, a radicarse en medios rurales, incluidas las pequeñas ciudades. Lo cual no niega que una parte $-y$ en algunos contextos la mayoría- de las familias indígenas rechacen la atención biomédica del parto no solo por la preferencia cultural por la partera tradicional o por el autoparto, sino por las formas negativas de trato, así como por el tipo de actividades de planificación familiar que les imponen, que pueden incluir la aplicación inducida o no de dispositivos intrauterinos, esterilizaciones y/o cesáreas. Esto lo sabemos a través de estudios que se han hecho en los últimos años en zonas indígenas de México (49). Lo que no sabemos es si estos procesos modifican las identidades y las cosmovisiones nativas y, sobre todo, cómo lo hacen.

No obstante, sabemos algunas cosas relevantes. En primer lugar, que la penetración biomédica opera sobre aspectos centrales de la identidad y la cosmovisión como son los que tienen que ver con el nacimiento, las enfermedades y la muerte. Segundo, que pese a la escasez de recursos e incluso del maltrato a que suelen ser sometidos por el personal de salud, los grupos étnicos siguen demandando servicios biomédicos, sobre todo para determinados problemas de salud. Tercero, que a nivel mexicano se documenta constantemente el descenso del número de curadores tradicionales; incluso en los grupos étnicos mayas de Chiapas y de Yucatán están desapareciendo los shamanes, que serían los actores sociales que no solo concentrarían, sino que utilizarían algunos de los contenidos más idiosincráticos de las cosmovisiones indígenas (h). Y recordemos que son dos de los estados con mayor porcentaje de población indígena $(51,52)$. Y cuarto, que el proceso de expansión biomédica, por lo menos en México, ha sido intermitente aunque se mantuvo constante desde finales del siglo XIX, y que se ha dado primero a través de campañas preventivas contra el tifus murino, la fiebre amarilla, el paludismo, la oncocercosis, y contra otras enfermedades infectocontagiosas que se desarrollaron en zonas de población indígena, y no indígena, y más tarde a través de las actividades clínicas (28). Aunque tampoco sabemos cómo la fuerte disminución e incluso erradicación de enfermedades, que eran algunas de las principales causas de mortalidad, influyeron o no en la aceptación de la biomedicina y en las modificaciones de las cosmovisiones étnicas.

No obstante, tenemos análisis que evidenciarían las consecuencias de la expansión de la 
sociedad dominante, incluida la biomédica. Y así Page, a partir de talleres realizados con población indígena de los Altos de Chiapas, concluye que:

Existe claridad en cuanto a que sus saberes ancestrales están casi totalmente perdidos, que de la religión maya queda muy poco; también que en las últimas tres décadas la costumbre se ha perdido a tal grado que ya hasta usan los vestidos de los mestizos, lo que tiene como consecuencia que ahora ya no reconozcan de donde viene cada quien, a qué pueblo pertenecen. (52 p.83)

Y si bien este autor señala que los sistemas de salud indígena son los que más han resistido, tanto su información como la de la mayoría de los analistas concluyen que el número de curadores tradicionales se reduce constantemente $(34,53)$.Varios especialistas señalan que los jóvenes indígenas ya no quieren ser "curanderos"; que varios curadores tradicionales en diversos grupos étnicos reconocen que cuando ellos mueran, ya nadie ejercerá la medicina tradicional en sus comunidades (i). Por lo cual, necesitamos observar la persistencia o las transformaciones de las cosmovisiones no solo en lo que se mantiene, sino también en lo que desaparece, sobre todo si lo que desaparece corresponde a algunos de los actores sociales que son los "encargados" de manejar las formas de saber indígena.

Los procesos de pertenencia e identidad de cualquier grupo subalterno, y no solo de los grupos étnicos latinoamericanos, tienen que ser pensados y analizados a partir de asumir que la mayoría de estos sectores necesitan desarrollar diferentes estrategias para sobrevivir, dados los bajos niveles de vida y la marginación a los que han sido sometidos, ya que han tenido y siguen teniendo los indicadores más negativos en términos económicos, educativos y de salud; además de ser los grupos más racializados en forma abierta o tácita. Por lo cual, tienen que valerse de todo aquello que esté a su alcance y les sirva para "aguantar" las situaciones a las que se enfrentan. Actualmente la mayoría de los sujetos y grupos indígenas migran, trabajan en lo que pueden, se organizan en movimientos locales para oponerse a la instalación de minas o de parques eólicos así como para negociar con las empresas para poder obtener algunos beneficios en términos de dinero y/o de trabajo. $\mathrm{Y}$ es por las mismas razones de supervivencia que también usan todo tipo de atención a su alcance, incluida la biomédica, para poder enfrentar sus enfermedades. Lo cual -y también lo subrayo- no supone que los grupos étnicos desaparecerán, sino que sobre todo cambiarán.

La mayoría de estos grupos no usan la medicina tradicional ni realizan rituales de sanación porque están pensando que, a través de estos, defienden su identidad cultural, y cuestionan la medicina de los actores sociales occidentales que los colonizaron y racializaron. La gente usa la medicina tradicional articulada o no con la biomedicina, con prácticas espiritistas o con rituales cristianos de diferente orientación para tratar de solucionar sus problemas de salud, en la forma más inmediata, eficaz y económica posible. Lo cual no niega que los rituales de sanación propios de los grupos son parte sustantiva de sus cosmovisiones, de su identidad y de su cohesión sociocultural; pero asumiendo que los sujetos y microgrupos actúan dichos rituales, al mismo tiempo que se inyectan antibióticos o ingieren vitaminas o analgésicos. Es decir, no niego que haya diferencias e incluso contradicciones entre las cosmovisiones nativas respecto de los procesos de s/e/a-p y las que se expresan a través de la biomedicina, pero -y es lo que tienen que explicar los especialistas en cosmovisiones- ello no impide que los pueblos originarios utilicen ambas, incluso simultáneamente.

Creo que en las comparaciones entre cosmovisiones operan varios sesgos metodológicos, siendo el primero comparar la cosmovisión biomédica con la cosmovisión indígena, cuando lo obvio metodológicamente sería comparar las cosmovisiones de los "mestizos" mexicanos, o las de los franceses con las cosmovisiones de los diferentes grupos étnicos mexicanos; así como las cosmovisiones de dichos grupos con las de los médicos y enfermeras que atienden en el primer, segundo o tercer nivel, así como con las de los shamanes, hueseros o parteras. Más aún tendrían que comparar, por ejemplo, las cosmovisiones del Ilamado "cinturón calvinista" de Holanda o de sectores medios urbanos de los EE.UU. con los saberes del personal de salud de sus respectivos países en torno, por ejemplo, al rechazo creciente a las vacunas que se observa en dichos grupos. Pero además, $-\mathrm{y}$ para 
mí es metodológica e ideológicamente decisivotoda cosmovisión debe ser descripta y analizada a través de las prácticas sociales, y no ser reducida exclusivamente a las "narrativas".

La existencia y el papel de las cosmovisiones, como vengo subrayando, los tenemos que observar en las representaciones y prácticas sociales de los diferentes sujetos y grupos y, sobre todo, en las prácticas, dado que a través de ellas vemos las articulaciones que estos realizan, así como las cosmovisiones que realmente utilizan. Y es en la "carrera del enfermo" o, si se prefiere, en la trayectoria de los padeceres en la que podemos observar cómo los diferentes grupos, incluidos los miembros de los grupos étnicos, utilizan las diferentes formas de atención a su alcance, más allá de que esas formas de atención correspondan a cosmovisiones diferentes, y aparentemente opuestas. Y obviamente las utilizan (eligen) a partir de sus posibilidades económico-sociales y no solo culturales (j).

Más aún, es en los procesos de autoatención donde podemos observar la persistencia de los saberes tradicionales, más allá de que hayan desaparecido o no los curadores tradicionales. Es donde podemos observar la persistencia del mal de ojo, de "limpias", o de las relaciones frío/caliente; así como observar los usos de hierbas convertidas o no en medicamentos herbolarios, una parte de los cuales pueden ser comprados en mercados "populares", en cadenas internacionales de supermercados o en tiendas "naturistas", y por supuesto en los viejos "huertos" y en los nuevos "jardines" herbolarios. Es especialmente en los procesos de autoatención del embarazo y del parto, vigentes aún en numerosos grupos étnicos desde Bolivia hasta México, donde podemos observar no solo su persistencia sino sus transformaciones, los cambios en los saberes tradicionales y la apropiación de nuevas formas de atención "paralela", además de la emergencia de nuevos curadores para padecimientos que exigen la existencia de un "otro" como curador.

Por lo menos, desde la década de 1940, algunos de los líderes académicos del indigenismo integracionista señalaron reiteradamente la tendencia de los grupos étnicos mexicanos a solicitar la instalación de escuelas, caminos, agua potable y centros de salud en sus comunidades, diferenciando con claridad que dichas demandas van junto con sus denuncias de cómo son tratados negativamente no solo por los mestizos que los explotan y discriminan racialmente, sino también por el personal de salud. Y así, por ejemplo, Aguirre Beltrán en 1955 señalaba el "prestigio inconmensurable que tiene la medicina científica entre la generalidad de la población, pero particularmente entre los grupos étnicos subordinados", así como pese a los maltratos y prejuicios del personal de salud hacia los indios, la biomedicina va siendo aceptada "lenta pero firmemente entre los grupos étnicos menos aculturados" (58 p.169), que es lo que reiteradamente señalan diferentes analistas hasta la actualidad $(51,52,59)$

En nuestro estudio sobre Yucatán confirmamos a finales de 1970, lo que autores como Erasmus (60) habían señalado para las comunidades de los grupos mayo de Sonora, es decir, no solo la penetración biomédica, por lo menos desde la década de 1930, en la población nativa, sino que dicha población atribuía a la medicina y especialmente a los antibióticos la reducción de la mortalidad, especialmente en sus hijos pequeños, señalando además que una parte de la población originaria en las décadas de 1940 y 1950 fue capacitada como "inyeccionista", es decir fue preparada para aplicar antibióticos, dado que ese fue el objetivo de la capacitación. Pero estos datos han sido también confirmados en las diferentes zonas indígenas por el indigenismo de participación, así como por los estudios etnográficos y por la información epidemiológica durante las décadas de 1980, 1990 y 2000, en las que emergía como una constante el reconocimiento por parte de los sujetos y grupos originarios de la eficacia de la biomedicina junto con la crítica y desconfianza hacia el personal de salud.

Pero gran parte de la desconfianza no solo refiere al maltrato, sino a que, como observamos en Yucatán a finales de los años setenta, los sujetos y grupos cuestionaban ser atendidos por pasantes, es decir, médicos aún no titulados profesionalmente, y señalaban la frecuente rotación del personal de salud, así como la frecuencia de sus inasistencias o llegadas tarde a la consulta. Además, establecían una valoración diferencial entre médico del centro de salud y médico de hospital, y entre médico privado y médico de los servicios oficiales de salud, e incluso entre las medicinas que les da la Secretaría de Salud y las medicinas que adquieren en las farmacias. Es decir, tenían una valoración 
más positiva de los servicios y productos privados, lo cual ha sido confirmado reiteradamente.

Desde hace casi cuarenta años sostengo que la mayoría de los sujetos y grupos étnicos de México puede ser que tengan contradicciones en términos de cosmovisión respecto de la biomedicina, pero no las tienen en términos de prácticas, lo cual no ignora que existan conflictos culturales y también sociales, sino que estos necesitan ser pensados desde la vida cotidiana de los sujetos y grupos. Los que ven conflictos y contradicciones en términos civilizatorios monolíticos y no monolíticos son, sobre todo, ideólogos indianistas y antropólogos sociales, que si realmente indagaran la vida cotidiana de los grupos étnicos observarían que la mayoría de los grupos indígenas no solo no rechazan, sino que, por el contrario, demandan atención y productos biomédicos. Lo que rechazan frecuentemente, en forma callada, es el tipo de relación médico/paciente, el maltrato del personal de salud, el racismo que les imponen las instituciones, darse cuenta que a la mayoría de los médicos y de los pasantes no les gusta vivir en sus comunidades rurales.

Más aún, si bien existen críticas de los grupos étnicos a la biomedicina en el plano de las representaciones sociales, estas no suelen incidir en el uso de los productos y servicios biomédicos o biomedicalizados, sobre todo en situaciones de urgencia. Lo cual no niega que haya tabúes, preferencias, oposiciones a ciertas prácticas y representaciones biomédicas, pero los estudios sobre atención y sobre trayectoria de enfermedad nos indican que los grupos sociales, incluidos los grupos étnicos practican una articulación de diferentes formas de atención a su alcance, y no un rechazo al "otro" occidental, por lo menos en términos biomédicos $(19,28,29)$.

Ahora bien, ¿qué significan -en términos de identidad, pertenencia, cosmovisión pero también de subjetividad- los procesos señalados, dado que estos pueden estar indicando cambios sustantivos hacia formas occidentales, como sería el caso de la creciente mercantilización de los curadores tradicionales? $(34,36)$. Entre otros aspectos, esto cuestionaría las expectativas colocadas en el desarrollo de "otro mundo posible" construidas, por lo menos parcialmente, a partir de las cosmovisiones de los pueblos originarios. Pero, y lo subrayo, sobre esto sabemos muy poco, por lo menos en relación con los procesos de s/e/a-p, tal vez porque los preocupados por objetivos políticos, si bien las nombran realmente incluyen muy escasamente el papel de las cosmovisiones y de las identidades étnicas en términos de procesos de s/e/a-p; y los preocupados por las cosmovisiones no nos aclaran qué papel cumplirían en los cambios políticos y económicos de los mundos posibles. O para ser más precisos, señalan y hasta defienden propuestas, pero sin que podamos observar el papel favorable, o no, que respecto de los procesos de s/e/a-p pueden estar generando las modificaciones en las cosmovisiones e identidades.

Como sabemos, las propuestas alternativas se hacen a partir de asumir que los grupos étnicos son por lo menos "diferentes", y que es a partir de esas "diferencias" que podemos pensar e impulsar otras formas de vida diferentes a las "occidentales" -o si se prefiere capitalistas- incluidas otras formas distintas de atender los padecimientos. $Y$ no cabe duda de que en los grupos étnicos existen "diferencias" no solo respecto de la sociedad no indígena, sino respecto de otros grupos étnicos, pero ¿en qué consisten en términos de cosmovisión, identidad, subjetividad, estas diferencias, como para a partir de ellas impulsar otros mundos posibles, incluidas otras formas de atención de los padecimientos? Y es respecto de este aspecto nuclear que, desde los procesos de s/e/a-p, observo que las propuestas son, por lo menos hasta ahora, básicamente ideológicas y de muy escasa precisión técnica y concreción práctica. Lo que no niega la creatividad y capacidad de lucha de una parte de los grupos étnicos americanos y de sus asesores para obtener tanto el reconocimiento social y legal, como el cumplimiento de las demandas territoriales que posibiliten su autonomía política y económica.

\section{LAS ORGANIZACIONES, LAS IDEOLOGÍAS Y LOS HECHOS}

En varios momentos, durante el siglo XX, surgieron en México movimientos ideológico-políticos, incluso armados, que intentaron modificar la situación de explotación, marginación y subordinación a que estaban sometidos los sectores sociales subalternos, pero hasta la década de 1970 
dichos movimientos no se hicieron en nombre de la etnicidad. Considero que, por lo menos, una parte de las organizaciones de curadores tradicionales que subrayan su identidad étnica diferencial $y$, en algunos casos, opuesta a la cultura y epistemología occidental, y que plantearon no solo formas paralelas de atención de la enfermedad, sino que también reclamaron autonomía para asegurar las orientaciones propias de su desarrollo, forman parte de dichos movimientos. Pero asumiendo que dichas organizaciones tuvieron una trayectoria de pocos años, y en su mayoría terminaron por languidecer o disolverse.

Es importante subrayar que casi todas estas organizaciones emergieron como paralelas a la biomedicina, y no como opuestas, aunque en algunas experiencias se acentuaron las críticas y diferendos con la biomedicina. Y así, por ejemplo, en Chiapas se formó en 1994 el Consejo de Organizaciones de Médicos y Parteras Indígenas Tradicionales (COMPITCH), constituida sobre todo por parteras, y que según los documentos de dicha organización, las parteras constituían un reservorio del saber ancestral de sus grupos pero no solo respecto de la salud, sino también de la "naturaleza". Más aún

La esencia indígena y femenina de los conocimientos de las parteras permitió visualizarlos además como saberes integrales que no solo se relacionan con la atención médica sino que también definen el cuidado del medio ambiente y la alimentación. [Su saber] es un don otorgado por Dios [y ejercido] desde dinámicas de solidaridad y de reciprocidad en el entorno social y material, respondiendo así a la voluntad divina. (61 p.216)

Se sostiene además que "Los conocimientos tradicionales de las parteras indígenas del COMPITCH se vuelven la fuente de una resistencia sociocultural que cuestiona desde una lógica y principios propios, la hegemonía del desarrollo neoliberal que conlleva al genocidio de su oficio" (61 p.6). Por lo cual, esta organización decidió -según Araya- defender sus comunidades de las opresiones biomédicas y de las agresiones a su medio ambiente, denunciando tanto la planificación familiar aplicada por las instituciones biomédicas, como la imposición de obligaciones personales impulsadas por los programas sociales federales y estatales contra la pobreza. Según esta y otros analistas, el sector salud y otras instituciones buscaron eliminar o por lo menos subordinar a las parteras empíricas, como parte de las políticas neoliberales del Estado mexicano, pero pese a ello las parteras habrían sostenido su autonomía, y junto con otras organizaciones de curadores tradicionales, como la Organización de Médicos Indígenas del Estado de Chiapas (OMIECH), en el año 2000 consiguieron la cancelación definitiva del proyecto Maya International Cooperative Biodiversity Group (ICBG-Maya) que buscaba apropiarse del saber tradicional sobre la flora regional y patentarlo a través de la acción de profesionales y empresas estadounidenses asociadas con centros de investigación y organizaciones nacionales $(62,63)$.

Pero además, la COMPITCH, no solo habría enfrentado y revertido "las estrategias de control corporativista del Estado mexicano para abogar por la recuperación, conservación y fortalecimiento de la medicina indígena..." (61 p.107), sino que hizo suyas las propuestas del Consejo Nacional de Médicos Indígenas Tradicionales (CONAMIT), que sostiene

\footnotetext{
La necesidad de que en el país se reconozca la existencia del sistema real de atención a la salud conformada por la medicina académica, la medicina tradicional y la medicina doméstica; y por lo mismo, la necesidad de realizar la programación en salud tomando en consideración la utilización y desarrollo de las tres instancias mencionadas [y el derecho de los curadores tradicionales a] participar en la elaboración de políticas y programas destinados a las comunidades indígenas. (61 p.105)
}

Estas propuestas en el campo de salud, si bien venían desarrollándose desde los años setenta, fueron en parte reimpulsadas, para algunos analistas, contradictoriamente (64), a partir del surgimiento del Ejército Zapatista de Liberación Nacional (EZLN) en 1994, lo cual posibilitó cuestionar el neoliberalismo tanto en términos de cosmovisión, como políticos, a partir de los procesos de s/e/a-p, como aparece documentado en el texto de Araya, así como impulsar las organizaciones 
de curadores tradicionales, y fundamentar la necesidad de autonomía de los pueblos originarios a través del uso de sus propias formas de atención a los padecimientos.

Por lo tanto, no puede negarse el proceso organizativo que se dio en los curadores tradicionales, así como el proceso de lucha ideológica impulsado a través de la reivindicación de la medicina tradicional no solo en términos de su eficacia técnica, sino de su capacidad para posibilitar la continuidad cultural y social de los grupos, dado que dicho saber médico tradicional constituiría la principal área de resistencia ante la expansión de las concepciones "occidentales", incluidas las biomédicas.

Unos pocos autores, por lo menos en México, adhirieron a la propuesta decolonial, de que el saber tradicional expresa una epistemología propia, a partir de la cual engendrar otra ciencia posible. Estas y otras propuestas, durante alrededor de dos décadas, dieron visibilidad y legitimidad a la medicina tradicional, convirtiendo a los curadores tradicionales en interlocutores del Instituto Nacional Indigenista (INI) y, en menor medida, del sector salud y de los programas contra la pobreza, por lo menos en algunos contextos nacionales.

Pero este proceso no tuvo demasiados resultados por lo menos en el campo de salud en los términos alternativos demandados sino que, por el contrario, posibilitó un mayor impulso de la biomedicina en términos de cobertura de servicios de salud, incluyendo las zonas indígenas de Chiapas, de tal manera que, según Graciela Freyermuth, como respuesta a la emergencia del movimiento zapatista, el gasto total en salud pasó en dicho estado de 2,06 millones de pesos en 1998 a 6,443,16 millones en 2012 (65 p.32-33). Pero además se acentuó la tendencia a la biomedicalización del trabajo de una parte de los curadores tradicionales, así como la subordinación o exclusión de las parteras empíricas.

Desde por lo menos mediados de la década de 1990, el sector salud aplicará toda una serie de medidas a nivel nacional, que se incrementarán en los últimos años, y que directamente excluyen del parto a las parteras tradicionales al establecer que todo parto debe realizarse en instituciones hospitalarias por lo menos del primer nivel, y en las que el parto esté exclusivamente realizado por médicos o por personal de salud acreditado profesionalmente. De tal manera que el papel de la partera tradicional queda reducido a ciertos controles durante el embarazo, a la educación respecto de los principales riesgos obstétricos, a la promoción del parto hospitalario y del uso de anticonceptivos, lo que se tradujo en que en 2013 solo el $1,51 \%$ de los partos fueran atendidos por parteras tradicionales. Pese a que el discurso del sector salud reconoce el papel de estas parteras, en los hechos se las subordina o excluye cada vez más (66).

Por lo tanto, no se logró integrar la medicina tradicional a partir de las propuestas de medicina "paralelas", ni mantener ciertos logros obtenidos como el de las organizaciones de curadores tradicionales. Es decir, no se pudo dar continuidad a estos y otros objetivos, debido a varias razones entre las cuales destaca el papel directo e indirecto de la biomedicina tanto a nivel del sector salud, como de la difusión de productos biomédicos y su legitimación a través de la experiencia de la población, e incluso el reconocimiento dado, sobre todo en la práctica, por el movimiento zapatista a las acciones de tipo biomédico $(67,68)$. Y además, como veremos más adelante, debido a la dependencia financiera, técnica e ideológica de las organizaciones médicas nativas.

En toda esta trayectoria, aparentemente paradojal, cumplieron un papel decisivo el INI "participacionista" y una serie de profesionales progresistas que fueron los que pensaron, planificaron e impulsaron los programas de "medicinas paralelas", la reivindicación ideológica y técnica de la medicina tradicional, y especialmente la creación de organizaciones de curadores tradicionales. Prácticamente, la totalidad de las organizaciones de curadores tradicionales, incluida COMPITCH, fue impulsada y/o directamente organizada por el INI y/o profesionales progresistas, en su mayoría médicos, que propusieron parte de los objetivos de dichas organizaciones así como participaron activamente en los procesos de organización, gestión y asesoría, pero subrayando además que en forma periférica operaron toda una serie de intelectuales, que cumplieron básicamente una función de legitimación académica con escasas intervenciones prácticas, aunque generando propuestas y expectativas ideológicas que frecuentemente contribuyeron a distorsionar la realidad. 
Considero que el texto de Araya, en el campo de los procesos de s/e/a-p, es un ejemplo de un tipo de producción académica que busca fundamentar procesos y el papel de actores sociales que les interesa defender, pero a través de información y de interpretaciones/afirmaciones no solo unilaterales, sino que tienen, por lo menos en parte, escasa relación con los hechos ocurridos y con las características de los actores sociales. Como en la mayoría de las zonas indígenas, en los Altos de Chiapas "La partera y el huesero poseen el status más bajo dentro de la estructura de la práctica curativa indígena" (53 p.82), por lo cual la partera empírica no expresa -según los propios curadores tradicionales- los aspectos centrales de la cosmovisión indígena como pretende la autora. Pero además, si bien las parteras participaron en las luchas contra el proyecto ICBG-Maya, los principales protagonistas fueron la OMIECH y sus asesores, que además contaron con el apoyo de ONG nacionales e internacionales (62). Justamente, esta situación secundaria de la partera empírica evidencia la situación de inferioridad social que tiene la mujer en la mayoría de los grupos étnicos, lo cual no desconoce los esfuerzos de sujetos y grupos internos y externos, como Araya, por elevar el estatus femenino, y por proponer una autonomía radical de las curadoras a partir de sus luchas. Pero como ya hemos señalado, las parteras no solo no han podido imponer su autonomía, como desea Araya, sino que cada vez están más excluidas de su principal objetivo como curadora: la atención del parto.

Por lo cual, los objetivos de Araya deben referirse a las representaciones y prácticas dominantes en los propios grupos étnicos, para no atribuir, por ejemplo, la subordinación de las parteras exclusivamente al sector salud, sino asumiendo la subordinación y secundarización de las parteras en sus propias comunidades tanto en términos de mujer como de curadora, como parte de los usos y costumbres actuales. A nivel de las autoridades locales, de la religión y de la sanación, el poder ha estado siempre en manos masculinas, y es a partir sobre todo de la apelación a los derechos humanos que sujetos y grupos originarios, ONG, asesores y otros grupos organizados, están tratando de modificar estas relaciones de poder interno que son parte no sé si de la cosmovisión, pero sí de los usos y costumbres de la mayoría de los grupos étnicos, y no étnicos de México.
Como sabemos el INI, la Secretaria de Salud y otras instituciones médicas, así como toda una serie de ONG variopintas formaron promotores de salud con orientación biomédica en zonas rurales. Además, desde finales de los años setenta, el INI desarrolló programas de capacitación de curadores tradicionales básicamente en la elaboración de productos y en la aplicación de tratamientos herbolarios para, en la década de 1990, impulsar la organización de médicos tradicionales a través de financiamientos nacionales e internacionales $(34,52,61)$, excluyendo en forma radical acciones de brujería. Y así Gallardo describe y analiza las consecuencias que esta orientación tuvo para la medicina tradicional en Cherán (Michoacán, México):

A inicios de los ochenta la medicina tradicional de Cherán sufrió un cambio que a futuro transformaría su desarrollo. A través del INI los especialistas fueron organizados y su práctica se sujetó a una serie de normas nuevas o diferentes. Estas incidieron en las relaciones entre los especialistas y restringieron la utilización de la magia, de la hechicería y de la "brujería" como alternativa terapéutica. Así como también modificaron las formas de transmisión del conocimiento médico tradicional. Antes de los ochenta este saber se transfería principalmente de un familiar a otro; de un adulto con experiencia hacia un joven aprendiz. Ahora, personas adultas pidieron ser "iniciadas" cambiando el significado cultural de la práctica médica y de las concepciones tradicionales de salud y enfermedad. La medicina tradicional se transformó en un oficio remunerativo... (34 p.157)

Agrega, además, que todo este proceso "se ha traducido en una especie de 'profesionalización' del médico tradicional... [lo que] ha significado que los especialistas hayan convertido a la medicina tradicional en una forma de empleo" (34 p.164).

Este proceso significó el reconocimiento institucional de los curadores tradicionales por parte del INI y, en menor medida, por instituciones del sector salud, lo que se expresó a través de talleres, reuniones y congresos organizados y financiados por estas instituciones, así como en la entrega de diplomas que los acreditaban como curadores 
tradicionales. La capacitación de las parteras empíricas, así como la construcción de hospitales mixtos o interculturales legitimaron inicialmente a los curadores tradicionales, pero también contribuyeron a la biomedicalización, institucionalización y subordinación de una parte de dichos curadores, así como a su mercantilización. Y, justamente, muchos de los conflictos que se van a suscitar dentro de algunas de las organizaciones de curadores tradicionales, así como la emergencia de nuevos curadores o la transformación de otros, tendrán que ver con cuestiones económicas, y con procesos de biomedicalización basados en la utilización de medicamentos de patente, lo que ya podía observarse desde mediados de la década de 1970 por lo menos en Yucatán $(28,29)$.

Correlativamente, como ya señalé, las organizaciones de curadores tradicionales, creadas por el INI en forma directa o inducida, permanecieron en una situación de dependencia financiera y técnica. Y si bien observamos intentos de autonomía en varias de estas organizaciones, dichos intentos no solo fueron escasos, sino que concluyeron, salvo excepción, en el repliegue o desaparición de estas organizaciones. Y una de las razones básicas de este proceso fue la reducción o directamente la falta de financiamiento. Es decir, estas organizaciones -así como los procesos de capacitaciónfueron pensadas e impulsadas desde fuera de los grupos étnicos, y por profesionales que no pertenecían a ellos, aun cuando habían establecido relaciones, a veces, muy profundas con los grupos étnicos. Los objetivos y las actividades, así como los congresos y talleres fueron propuestos, financiados y coordinados por los asesores, y no por los curadores tradicionales. Lo cual no niega, que una parte de los curadores tradicionales tuvieran una participación activa en el desarrollo y mantenimiento de los objetivos de estas organizaciones e intentaran darle continuidad.

Pero reitero que, si bien reconozco los objetivos ideológicos y técnicos que guían estas lecturas y acciones por parte de los asesores profesionales y por líderes indianistas buscando un sujeto autónomo, persistente y opuesto o, por lo menos, cuestionador de "Occidente", no termino de entender la lógica que opera en los antropólogos cuyo campo de acción es, en la inmensa mayoría, exclusivamente académico, más allá de que de tanto en tanto firmen -firmemos- denuncias colectivas.
Y así, por ejemplo, para algunos de ellos la cuestión de la disminución, desaparición o transformación de los curadores tradicionales y especialmente de los shamanes, se convierte en una especie de cruzada y en una búsqueda o justificación de la existencia y persistencia de los shamanes, aun cuando todos los datos indican que, por lo menos, para Yucatán y para los Altos de Chiapas los shamanes han desaparecido, están en vías de extinción o los encontramos reemplazados y a veces transformados en curadores tipo new age.

Ahora bien, en términos políticos no me preocupan tanto los sesgos académicos, sino el papel de los líderes indianistas. Y es por ello que, frente a los discursos de los líderes que apelan a la cosmovisión y el saber de los pueblos originarios, me pregunto si a través de dichos líderes habla el conjunto de la población indígena; si los líderes expresan las demandas y necesidades de la población, o si hablan básicamente a partir de sus propios objetivos políticos e ideológicos, que pueden expresar -o tal vez no- los objetivos de los sujetos y conjuntos sociales. Por lo cual sería importante observar a través de estudios el distanciamiento o la convergencia que existen entre los discursos de los líderes etnicistas y también no etnicistas, y las representaciones y prácticas de los sujetos y grupos que dichos líderes representan.

Considero que, en función de sus propios objetivos, una parte de los líderes se distancian cada vez más de las prácticas de la población, por lo menos respecto de los procesos de s/e/a-p, y pese a que dichos líderes saben de los usos cada vez más constantes de la biomedicina por los grupos étnicos. Aclaro que no estoy proponiendo que el saber del "pueblo" es el correcto, y que no lo es el de los líderes, sino que lo que me interesa es establecer el saber de los sujetos y grupos que operan en la realidad: si estos se oponen en la práctica a los usos biomédicos, y si los líderes trabajan o no con dichos saberes o los reformulan ideológicamente en función de sus propios objetivos.

Cuando una parte de estos líderes cuestiona que las organizaciones de médicos indígenas venden sus productos medicinales, y proponen que los curadores tradicionales formen parte de los equipos de salud y reciban salarios y prestaciones, podemos entenderlo, por un lado, como cuestionamiento al mercantilismo médico y, por otro, como forma de subrayar las obligaciones 
sociales de un estado neoliberal que trata de desentenderse de por lo menos una parte de ellas. Pero dichas propuestas tienen poco que ver, no solo con los objetivos y la ideología del sector salud, sino también con los objetivos y necesidades de la medicina tradicional entendida en términos de cosmovisión; aunque sí puede tener que ver con las necesidades de una parte de los curadores tradicionales.

\section{BIOMEDICINA: LAS CRÍTICAS EQUIVOCADAS}

La biomedicina es la forma de atender y prevenir enfermedades que más se expande a nivel mundial. Análisis, frecuentemente superficiales, señalan la expansión de formas "orientales" de atención y sanación en los países occidentales, pero sin informar sobre la constante expansión de la biomedicina sobre las sociedades asiáticas y africanas.

Actualmente la India, uno de los países que exportaría en forma directa e indirecta gran parte de las técnicas de sanación no occidentales, es el país que tiene el más alto consumo de antibióticos del mundo, lo cual se ha convertido en un hecho casi imposible de contener dada la facilidad con que la población hindú tiene acceso a estos medicamentos, y a la masividad de su consumo. Dicha masividad es producto, al igual que en Occidente, de la fuerte tendencia de los médicos hindúes a recetar antibióticos innecesariamente, a los intereses y presiones de la industria químico/farmacéutica, así como a la rápida eficacia encontrada en los antibióticos por la población hindú. Una de las paradojas de este proceso es que, para revertir esta tendencia, se está reimpulsando el uso de las medicinas ayurvédica, siddhi, yumani, yoga y también la homeopatía, aunque sin conseguirlo, por lo menos hasta ahora.

Ahora bien, el $76 \%$ del incremento en el uso de antibióticos durante el período 2010-2013 se concentra en los países que integran el BRICS (k), al cual pertenece India. Si bien para algunos analistas, el BRICS puede constituir una alternativa económica de ayuda a países latinoamericanos, no cabe duda que no lo es respecto de ciertos procesos de s/e/a-p, ya que la resistencia a los antibióticos se va constituyendo en una de las principales amenazas a la salud, especialmente para los países periféricos, dada la posible expansión de las viejas y nuevas enfermedades infectocontagiosas. Lo cual no ignora que, según la OMS, el $80 \%$ de la población de los países en desarrollo depende de la medicina tradicional para resolver los problemas de salud más comunes y frecuentes y que, según la OPS, el $80 \%$ de la población indígena de las Américas utiliza los curadores tradicionales como principal prestador de asistencia sanitaria (69 p.37), aunque considero que este último dato es producto de una manera "tradicional" de producir etnografías o encuestas dado que, por ejemplo, no consideran que una parte creciente de la población originaria, incluidos los curadores tradicionales, utilizan fármacos.

Sin embargo, lo importante a asumir es que si bien la mayoría de la población del planeta no tiene acceso a la atención biomédica, observamos una tendencia constante a la expansión de la biomedicina a través de fármacos, como es el caso de la India y los países del BRICS que, recordemos, constituyen casi el 50\% de la población mundial. Este proceso de expansión también podemos observarlo a través de la lucha contra el VIH-sida en países africanos y del sudeste asiático y, más recientemente, con la epidemia de Ébola, ya que en un país africano como Liberia donde solo existen 120 médicos para 4 millones de personas, a principios de 2015 se estaban probando varias vacunas para inmunizar a la población. La biomedicina, como parte del sistema capitalista en sus diferentes variantes, tiende a la expansión constante para asegurar su reproducción, por lo cual desde sus objetivos intencionales y funcionales todavía hay una enorme población que la está aguardando a partir de sus propios objetivos y necesidades.

Cuando en la década de 1970, intelectuales latinoamericanos preocupados, tanto por las orientaciones negativas que se estaban dando dentro de la biomedicina, como por la participación popular en salud, proponían como modelo alternativo o por lo menos complementario de atención de la enfermedad, a los promotores de salud denominados "médicos descalzos" que había impulsado el maoísmo en China, no señalaron que dichos promotores de salud no fueron a las comunidades rurales solo para rescatar las 
medicinas tradicionales locales, sino principalmente para impulsar las actividades biomédicas de vacunación, de atención del parto, y las que tienen que ver con la higiene personal y el saneamiento del medio ambiente. La rehabilitación de la medicina china bajo el maoísmo tuvo sobre todo un objetivo ideológico, tal como -según algunos autores- está ocurriendo actualmente con la medicina tradicional en el caso de algunos países latinoamericanos (70).

Pero lo que me interesa subrayar es que la medicina tradicional china se articuló ideológicamente con el impulso a la biomedicina, dadas las características atribuidas a esta última. Y así el gobierno comunista chino impulsó la medicina occidental, más allá de sus críticas y enfrentamientos con los países capitalistas "occidentales", dado que la biomedicina, si bien se concretiza dentro de países capitalistas, no se identifica con ningún régimen político ni ideológico ni siquiera cultural (I), sino que se identifica con "la ciencia". Más aún, las únicas organizaciones internacionales referidas a los procesos de s/e/a-p, y en las cuales participan oficialmente todos los países, son de tipo biomédico, como ocurre con la OMS, con el Fondo de las Naciones Unidas para la Infancia (UNICEF) $y$, en cierta medida, con Médicos Sin Fronteras. Mientras que las medicinas "paralelas" solo han dado lugar al desarrollo de redes más o menos minoritarias de usuarios y/o de profesionales, frecuentemente asociadas a la biomedicina y cuya continuidad está permanentemente en duda.

Como ya lo señalamos, cuando a principios de la década de 1980 surgió una nueva enfermedad Ilamada VIH-sida, o en la actualidad con la expansión del Ébola, los países a nivel individual y colectivo buscaron y siguen buscando la solución en productos y concepciones biomédicas, y no en la medicina mandarina, en la medicina ayurvédica, en las medicinas tradicionales africanas o latinoamericanas ni en las medicinas new age. $\mathrm{O}$ mejor dicho, muchos las siguen buscando en las medicinas "paralelas", pero hasta ahora la única que aplica soluciones parciales o más o menos definitivas para el VIH-sida o para el Ébola es la biomedicina. Las acciones biomédicas no solo consiguieron reducir la expansión del virus y la mortalidad generada por él, no solo están desarroIlando vacunas para controlarlo en el futuro, sino que los que enfermaron y murieron por salvar a la población de estos países africanos -alrededor de 366 entre principios de marzo y finales de diciembre de 2014 (72)- fueron médicos y personal sanitario biomédico, algunos de los cuales fueron asesinados cuando trataban de desarrollar tareas preventivas $(\mathrm{m})$. Lo cual implica reconocer, más allá de las críticas que podemos hacer a la biomedicina, su notable hegemonía actual y, a través de ella, la persistencia de la hegemonía occidental no solo en términos científicos y técnicos, sino también culturales e ideológicos. Que además, y lo subrayo, constituye la forma más insidiosa del poder hegemónico, dado que la biomedicina aparece como un referente universal que está más allá de cada cultura, sociedad o nación. Y por eso tanto las sociedades occidentales, como todos los países a nivel mundial, impulsan el uso de la biomedicina, e incluso proponen la construcción de sistemas de salud generales y gratuitos basados en la biomedicina como, por ejemplo, es el caso actual del gobierno proindígena de Bolivia.

Ahora bien, y retomando los interrogantes formulados previamente, no cabe duda de que por lo menos en América Latina asistimos a una constante expansión de la biomedicina, pero dicha expansión ¿implica modificaciones en las identidades y cosmovisiones de nuestros grupos étnicos? Y, sobre todo, dichas modificaciones ¿han sido tenidas en cuenta por los líderes de los movimientos étnicos y por sus intelectuales orgánicos? Yo no tengo respuestas seguras respecto de estos interrogantes, dado que no contamos con estudios profundos sobre estos aspectos, aunque sí con una diversidad de opiniones fuertemente ideologizadas. De los materiales analizados y respecto del primer interrogante surge que, por lo menos en parte, las cosmovisiones y sobre todo las prácticas, respecto de los procesos de s/e/a-p, se están modificando en los grupos étnicos americanos. En países como México se señala que las representaciones sociales de determinados grupos étnicos respecto de la enfermedad y su tratamiento se han ido modificando especialmente por la influencia de las iglesias católicas y protestantes. Además, la reducción, desaparición o transformación de los curadores más emblemáticos en términos de cosmovisión, es decir, los shamanes, evidencia, por lo menos, la pérdida de alguno de los principales sostenes y reproductores de las cosmovisiones. Lo cual en cierta medida se verifica, como ya lo 
señalamos, a través de lo que está ocurriendo con los sueños y con los "lectores" de estos, por lo menos en los Altos de Chiapas. Pero también se observa en una serie de procesos, de los cuales solo presentaré tres que expresan situaciones distintas aunque complementarias.

Como sabemos, entre los mayas yucatecos, los shamanes tienen un papel decisivo en la realización de rituales colectivos vinculados con enfermedades, con la producción agrícola, o con ceremonias familiares, existiendo además una diferenciación estratificada entre "maestros" y "aprendices" en el manejo de estos rituales. Según algunos analistas se está dando una situación cada vez más común, según la cual los jmeeno'ob con cierto reconocimiento deciden dedicarse únicamente a realizar curaciones y autoexcluirse de los rituales colectivos agrarios por ser estos muy "peligrosos" y/o muy "cansados"; además de que ello implica abandonar la milpa (plantío de maíz), la familia, el trabajo, según ellos mismos expresan (73). Por consiguiente, dejan encargados de los trabajos grandes o colectivos a jmeeno'ob en proceso de instrucción (73 p.186). Los "maestros" se dedicarían exclusivamente a actividades terapéuticas, porque además "suelen obtener remuneración económica importante" (73 p.186).

Pero un aspecto básico que señalan estos autores es que uno de los principales rituales comunitarios que realizaban los shamanes yucatecos es el ritual agrario ch'a chák, el cual ha disminuido notoriamente, dado que la población maya trabaja cada vez menos en la milpa debido a la baja remuneración obtenida. Por lo cual va desapareciendo uno de los principales espacios de reproducción de la cosmovisión e identidad maya, subrayado por los autores mencionados. Si bien estos rituales agrarios ya se estaban reduciendo a finales de los años setenta según observamos entre 1977 y 1980 en la zona yucateca de Ticul; lo más significativo es que conjuntamente con esta reducción, los shamanes importantes dejan de participar en ellos, delegándolos en aprendices, mientras se dedican exclusivamente a realizar actividades terapéuticas mercantilizadas. Y todo ello, dentro de un desarrollo de tendencias sanadoras tipo new age impulsadas por el gobierno, por intelectuales y por sectores sociales medios, relacionadas en gran parte con el turismo.
El segundo caso es por lo menos paradójico. Como sabemos, Cuba ha desarrollado una industria de la atención médica que cumple funciones económicas e ideológicas para el gobierno cubano, y que ha evidenciado su gran capacidad técnica y solidaria en gran cantidad de situaciones graves, especialmente en países periféricos. En función de ello, Cuba ha establecido acuerdos para instalar en las comunidades más pobres y marginadas rurales y urbanas de varios países latinoamericanos, médicos cubanos a tiempo completo, recordando que, en naciones como Bolivia, gran parte de esas comunidades son indígenas.

La paradoja radica en que dichos médicos cubanos caracterizados por su excelente formación técnica, y por el buen trato a los pacientes como lo han demostrado las evaluaciones de su desempeño, se caracterizan por una formación biomédica que excluye toda consideración científica y técnica respecto de las medicinas tradicionales, y de las creencias religiosas. Más aún, nos encontramos con la paradoja de que sujetos de origen indígena, a partir de sus objetivos personales, y comunidades originarias latinoamericanas han decidido ir a estudiar o enviar jóvenes a estudiar medicina en Cuba, pese a que la formación que obtienen cuestionará aspectos centrales de las cosmovisiones indígenas respecto de los procesos de s/e/a-p (n).

El tercer proceso refiere a los hospitales mixtos o interculturales que, en los casos que conozco para México, ninguno ha sido demandado por los grupos étnicos, sino que han sido propuestos y organizados por el INI o por los gobiernos de algunos estados, subrayando que los hospitales interculturales del estado de Puebla han sido construidos como parte de las actividades de ecoturismo relacionadas con el denominado Plan Puebla/Panamá (74 p.394). La mayoría de los curadores tradicionales se han opuesto a dichos hospitales, ya que para los curadores chiapanecos, por ejemplo, en estos hospitales se descontextualiza la práctica médica tradicional, señalando que "no es posible juntar a los doctores con los médicos tradicionales porque las medicinas son muy diferentes, no tienen nada que ver con las otras" (52 p.94-95). Una de las razones por la cual una parte de los curadores tradicionales se interesaron por trabajar en estos hospitales es económica, pues pensaban que tendrían una demanda que les redituaría ganancias 
y, por ello, en el hospital mixto de Cuetzalan (México) se había propuesto la atención diaria, pero que a partir de 1994 se redujo solo a los jueves y domingos, que son los días de mercado. En los hospitales mixtos de Puebla la demanda no solo es muy escasa, sino que parte de esa demanda corresponde a sectores no indígenas.

Es importante subrayar que, en la mayoría de los países latinoamericanos, los hospitales y centros de salud interculturales han evidenciado los mismos problemas, incluso en el país con mayor porcentaje de población originaria, ya que en Bolivia, al igual que en México, los centros de salud mixtos no fueron solicitados por la población indígena ni por los curadores tradicionales sino que fueron pensados y organizados por las ONG, los antropólogos sociales y algunos funcionarios. Al igual que en México, se caracterizan por la falta de demanda por parte de la población indígena $(75,76)$.Y así, por ejemplo, en el hospital intercultural, localizado en San Pedro de Curva, comunidad relativamente cercana al lago Titicaca, durante los años 2003, 2004 y 2005 hubo 34 visitas de pacientes al consultorio de medicina tradicional, es decir 11 consultas por año, de las cuales 18 fueron de turistas extranjeros (77).

Si bien la poca demanda de atención que se observa en estos hospitales, así como el rechazo de trabajar en ellos por la mayor parte de los curadores tradicionales, expresan su fracaso, considero que la existencia de estos hospitales evidencia las concepciones y relaciones de hegemonía/subalternidad que constantemente se lanzan a la población indígena y no indígena, ya que más allá de su subutilización, dichas instituciones ponen de manifiesto los recursos diferenciales que utilizan la biomedicina y la medicina tradicional, el lugar marginal que tienen los servicios tradicionales dentro del hospital, las características diferenciales de los consultorios y salas de espera, así como las "distancias" sociales que operan entre curadores biomédicos y tradicionales. Lo interesante es que las propuestas y la puesta en funcionamiento de estos centros de salud interculturales se hicieron pensando en que ayudarían a cuestionar las relaciones de hegemonía/subalternidad; más aún, algunos las veían como contrahegemónicas.

En el caso del segundo interrogante, considero que una parte de los líderes políticos y de los intelectuales orgánicos, si bien saben de la expansión y del papel hegemónico de la biomedicina y de sus efectos positivos sobre los padecimientos que más afectan a las comunidades indígenas, tienden a sostener a nivel de discurso la defensa de una "tradicionalidad" que opera en términos ideológico-políticos como justificación de sus propuestas etnicistas sin desconocer por ello el papel de la biomedicina, pero colocando el peso del discurso en la "tradicionalidad". Y este discurso complementario, que no es doble discurso, es el que por una parte apoya el mantenimiento ideológico de una identidad étnica propia, al mismo tiempo que incluye lo que la población indígena hace en la vida cotidiana, es decir, utilizar tanto lo tradicional como lo biomédico.

Considero que el caso boliviano evidencia casi paradigmáticamente lo que estamos señalando, dado que el gobierno de Evo Morales no solo tiene un discurso identitario referido a la medicina tradicional, sino que ha creado un Subministerio de Medicina Tradicional y Salud Intercultural pero, sin embargo, los recursos para la salud del estado boliviano no van hacia la medicina tradicional sino que, en su totalidad $-y$ subrayo en su totalidad-, van hacia personal y acciones biomédicas $(76,78)$. Más aún, el gobierno boliviano plantea desarrollar un sistema de salud universal basado en la biomedicina, dado que es una de las principales demandas de la población. Y recordemos que Bolivia es el país con mayor porcentaje de población indígena, ya que para finales de 2010 constituía el $50 \%$ de dicho país, mientras que en México solo corresponde al 13\% (69).

Es decir que la medicina tradicional, como parte sustantiva de la cosmovisión e identidad de los grupos étnicos, es usada, junto con otros saberes tradicionales, a nivel de discurso político-ideológico, mientras que en los hechos se impulsa y financia la biomedicina. Lo cual no supone la negación, y menos aún desprecio y/o subvaloración de la medicina tradicional por los dirigentes políticos bolivianos, sino reconocer que la eficacia técnica y la legitimación social están colocadas en una biomedicina, que además es cada vez más demandada y usada por los pueblos originarios. Esta conclusión es reforzada por el hecho de que, en 2014, Evo Morales volvió a ganar las elecciones presidenciales, obteniendo la mayoría de votos en todas las zonas indígenas, incluso en aquellas donde pocos años antes se 
generaron conflictos por cuestiones territoriales. Un presidente que, además, accede ritualmente a su cargo presidencial a través de ceremonias más o menos ancestrales.

Como sabemos, en América Latina tenemos líderes políticos e intelectuales que denuncian no solo la penetración de la biomedicina en las sociedades nativas, sino que subrayan la incompatibilidad entre las cosmovisiones indígenas y las occidentales, lo cual se evidenciaría a través de los procesos de s/e/a-p; propuestas que cada vez tienen menos que ver con lo que realmente hacen los grupos étnicos con dichos procesos, lo cual inevitablemente los Ileva a un distanciamiento con dichos grupos. Considero que estos líderes políticos y, sobre todo, algunos intelectuales (79), no han descripto y menos trabajado sobre los procesos de s/e/a-p que operan en los grupos étnicos, sino que sus referencias a la biomedicina las utilizan en función de sus objetivos ideológicos, y en menor medida políticos. Más aún, las utilizan desde perspectivas etnicistas de tipo nacionalista o socialista, o a través de una articulación de ambas, para impugnar tanto al capitalismo como a la cosmovisión occidental en función de sus objetivos económico-políticos, que cuando logran institucionalizarse, por lo menos hasta ahora, han concluido en alguna variante de capitalismo. Esto ha sido analizado para procesos muy dispares ocurridos en países de América Latina y del Caribe (27), incluso respecto de la trayectoria del EZLN (80-82) para evidenciar los usos de la etnicidad como estrategia política, pero recordando que los usos del etnicismo como estrategia política fueron llevados, entre las décadas de 1920 y 1940, casi hasta sus últimas $(\dot{i}$ ?) consecuencias por movimientos sociales y organizaciones políticas europeas, aunque con objetivos muy diferentes. Por lo cual, como ocurre en la mayoría de los procesos, los usos de la etnicidad y sus consecuencias deben ser referidos a las fuerzas sociales que se hacen cargo de ella y no a la etnicidad en sí (3).

Ahora bien, más allá de la validez de dichos usos instrumentales, una de las principales cuestiones para nosotros está en observar si las representaciones y las prácticas biomédicas penetran, modifican, hegemonizan o no los comportamientos, las cosmovisiones o, si se prefiere, los usos y costumbres de los grupos étnicos. Es decir, si se convierten en parte de su cultura, más allá de que a nivel verbal se impugnen la sociedad y los valores "occidentales".

En términos de movimientos étnicos y sobre todo de sus objetivos políticos, tanto entre los líderes como entre quienes se dedican a analizar procesos políticos, observamos que las cosmovisiones, y en particular las que se expresan a través de los procesos de s/e/a-p, constituyen procesos secundarios y frecuentemente irrelevantes más allá de los usos tácticos y coyunturales que hagan de estos. Más aún, considero que existe toda una serie de procesos de s/e/a-p a través de los cuales se evidencia la penetración biomédica en los usos y costumbres de los grupos étnicos, pero que casi no han generado en los líderes políticos y académicos reflexiones sobre los cambios en las cosmovisiones indígenas referidas a la enfermedad y su atención y prevención afectadas por dicha penetración. Algunas de las más fuertes y constantes agresiones físicas y culturales impulsadas por el sector salud han sido muy poco denunciadas por los líderes indianistas, por las ONG y por los académicos. Y me refiero a los programas de planificación familiar y de salud reproductiva impulsados, especialmente, desde mediados de la década de 1970 hasta casi finales de la de 1990 por el sector salud de la mayoría de los países latinoamericanos y del Caribe. Programas que buscaron reducir radicalmente las tasas de natalidad, y en los cuales la esterilización de mujeres se constituyó en la principal técnica de control de la natalidad (5).

Ahora bien ¿por qué la mayoría de las ONG afines y no afines a los grupos étnicos, que trabajan sobre procesos de s/e/a-p, especialmente las que trabajan sobre salud reproductiva, denunciaron y se opusieron tan poco a las esterilizaciones; o cuando las denunciaron, lo hicieron durante un pequeño lapso, pese a que la esterilización sistemática duró más de dos décadas? Pero además ¿por qué la gran mayoría de los movimientos indianistas casi no dijeron nada al respecto, no formando parte de sus demandas ni de sus luchas? Estas ausencias son aún más notorias porque el lapso de mayor intensidad de la aplicación de los programas de planificación familiar $y$, especialmente, de esterilizaciones coincide con el periodo de mayor frecuencia e intensidad de los movimientos indios en América Latina. 
¿Será acaso que las esterilizaciones de mujeres no afectan la identidad y la cosmovisión étnica? Y si fuera así ¿qué sería entonces lo que las afecta? $\mathrm{Si}$ bien en varias regiones indígenas mexicanas -como la de los Altos de Chiapas- hubo una oposición silenciosa a dichos programas, sin embargo, en Yucatán -el estado mexicano con mayor porcentaje de población indígena- hubo un rechazo muy escaso no solo a las esterilizaciones sino a las histerectomías (83). Pero más allá de reconocer estas diferencias entre grupos mayas, necesitamos preguntarnos ¿qué expresan esas omisiones en el caso de las ONG y sobre todo de los movimientos indígenas? Mientras en el caso de la mayoría de las ONG, incluidas las feministas radicales, expresa por una parte conflictos ideológicos y éticos, dado que en gran medida están de acuerdo con la planificación familiar, aunque frecuentemente no en la forma en que es aplicada; por otra, dichas ONG suelen estar "atadas" a financiamientos que promueven dicha planificación (84). Es decir, tanto por sus objetivos ideológicos feministas, por sus concepciones biomédicas, como por sus fuentes financieras de mantenimiento, investigaron muy poco, y menos aún se movilizaron contra las esterilizaciones.

En el caso de los movimientos étnicos tengo pocas explicaciones más allá de asumir, como señalé previamente, que la mayoría de los líderes se ha preocupado escasamente por el papel de los procesos de s/e/a-p en el desarrollo de sus objetivos y movilizaciones políticas, aun cuando pueden Ilegar a utilizarlos ideológicamente como parte de sus estrategias etnicistas; lo cual no es solo una característica de estos grupos, sino de los movimientos sociales liderados, en su mayoría, por varones. Pero ocurre que la planificación familiar, y aún más las esterilizaciones, no constituyen procesos secundarios y menos invisibles, aun cuando los medios de comunicación masiva difundieron fuertemente la planificación familiar, pero silenciaron las esterilizaciones, en lo cual convergieron con las ONG, con los movimientos indios y con el sector salud. Necesitamos subrayar que la planificación familiar y, sobre todo, las esterilizaciones, no solo violentan a la mujer, sino que se supone violentan una masculinidad que hasta hace pocos años sostenía que "la mujer siempre debe estar cargada, como el fusil", y que era señalado como uno de los principales indicadores del "machismo" mexicano. Pero ahora no vamos a analizar estos aspectos, que no obstante serían parte de la cosmovisión o de los usos y costumbres del campesinado mexicano indígena y no indígena y que, sin embargo, se modificaron rápidamente en la mayoría de los contextos nacionales, sin que casi se dieran oposiciones a las esterilizaciones.

La planificación familiar fue el mecanismo a través del cual en México se redujo el número de hijos por mujer de 6,5 en la década de 1970 a 2,2 en la actualidad; y cuyo alto número no solo tenía objetivos económicos para los campesinados indígenas y no indígenas, sino que evidenciaba la fuerza genésica masculina, y la gran fertilidad femenina en una articulación de concepciones cristianas y precristianas. Pero además la planificación familiar en sus propuestas y acciones iniciales implicó que fuera el Estado quien impusiera/sugiriera el número de hijos a tener, y no el varón o el grupo familiar; más aún fue el Estado quien colocó en la mujer y no en el varón la posibilidad de un real control de la natalidad. Pero esa inducción del Estado ha sido asumida, según algunos expertos, por la población: "En Chiapas las mujeres están teniendo menos hijos que nunca y les gustaría que sus hijos, a su vez, tuvieran menos hijos" (74 p.158). Y podríamos seguir abundando en posibles contenidos de la cosmovisión y de la identidad indígena, así como en los mecanismos de transformación a través de procesos de s/e/a-p, pero lo que ahora me interesa subrayar es la escasa o nula movilización de los movimientos nativos respecto de un proceso, durante el cual las instituciones del sector salud también trataron de esterilizar a varones indígenas (o).

\section{IDEOLOGÍAS, PROYECTOS Y POSIBILIDADES}

De los procesos de s/e/a-p analizados surgen algunos hechos interesantes que trataré de sintetizar. En principio observamos que el papel dado a las cosmovisiones indígenas como alternativa social e ideológica no va más allá, por lo menos hasta ahora, de las retóricas académicas y políticas, dado que el principal reservorio y operador de dicha cosmovisión, según los especialistas, es 
decir, los curadores tradicionales, no es realmente tomado en cuenta en términos políticos ni económicos tanto por los líderes movimientistas, como por los grupos étnicos que han accedido al poder. Más aún, asistimos a un proceso de desaparición o de transformación de la mayoría de los principales curadores tradicionales, sin que esto preocupe en términos políticos ni ideológicos.

Si bien la defensa y legitimación de la medicina tradicional se monta, en gran medida, sobre su eficacia respecto de ciertos padecimientos y su papel en la cohesión, pertenencia e identidad de los grupos, así como en su diferenciación y crítica de la medicina, no sé cuál es su propuesta de sector, y ello por dos razones básicas. En primer lugar, porque no sabemos cómo a través de la medicina tradicional vamos a reducir o eliminar las enfermedades de las cuales muere la población en los diferentes contextos étnicos y no étnicos (p). Y, segundo, porque sabemos que la medicina tradicional no ha podido reducir las principales causas de muerte en sus propios grupos étnicos, debido en gran medida a que la mayoría de los padecimientos a través de los cuales se reconoce la eficacia de los curadores tradicionales tiene que ver con padeceres generados por relaciones sociales, especialmente los que se organizan en torno a la envidia, a las transgresiones sociales, al no cumplimiento de normas y rituales. Lo cual no niega el papel que puede cumplir a nivel microgrupal y comunitario tanto de eficacia simbólica como técnica (51) (q), pero que implica un trabajo teórico y práctico de justificación y articulación que, no niego que exista, pero que desconozco por lo menos para México, ya que una cosa es defender la medicina tradicional en términos ideológicos y técnicos, y otra pensarla en términos de políticas de salud/enfermedad. Por lo cual, creo que una de las tareas básicas para los analistas y sobre todo para los líderes indianistas es justamente pensar e impulsar esta posibilidad.

A través de los materiales analizados observamos un proceso de organización y empoderamiento de los curadores tradicionales, de defensa de la medicina tradicional y de sus curadores en términos de su eficacia simbólica, social y física, que incluyó la demanda de su legalización; un cuestionamiento de las concepciones y prácticas biomédicas, así como propuestas e intentos de autonomía. Y si bien, como se señaló, se lograron ciertos objetivos, los resultados son por lo menos preocupantes desde las perspectivas etnicistas. La información indica que sigue expandiéndose la biomedicina; que se reducen, desaparecen o se subordinan una parte de los curadores tradicionales; que las organizaciones de médicos tradicionales han desaparecido, reducido el número de miembros o se han limitado a un mínimo de acciones, y que las expresiones autonómicas en términos de objetivos y organización, si bien siempre fueron escasas, actualmente han desaparecido. Más aún, la orientación hacia una práctica de los curadores tradicionales basada en la herbolaria y la exclusión de los aspectos "mágicos" impulsada por el INI, por las diferentes iglesias cristianas, por funcionarios de los gobiernos estatales y/o por institutos de investigación; así como el creciente uso de fármacos y la mercantilización de la atención por una parte de los curadores tradicionales, indica la falta y/o reducción de su autonomía técnica, así como la penetración no solo técnica sino ideológico-cultural de la biomedicina. De hecho, la medicina tradicional ( $r$ ) que se expande es la que se expresa a través de formas de sanación new age o similares.

Como lo señalamos, la casi totalidad de procesos organizativos, objetivos técnicos e ideológicos y cuestionamientos fueron generados, impulsados, asesorados y/o financiados por instituciones y/o profesionales e intelectuales que no pertenecen a los grupos étnicos, y de los cuales las organizaciones mantuvieron una dependencia, por lo menos parcial, a través de todo el proceso. Gran parte de las críticas a la biomedicina, como la validación técnica y cultural de la medicina tradicional, por dar dos ejemplos, no surgen de los grupos étnicos sino de las elaboraciones de profesionales, académicos y de intelectuales más o menos orgánicos. Lo cual no cuestiono, sino que recuerdo para tratar de entender por qué en México, luego de más de dos décadas de trabajo organizativo, las organizaciones de curadores desarrolladas en nombre de las cosmovisiones y técnicas sanadoras tradicionales decaen hasta casi desaparecer. Y, paradojalmente, se desarrollan nuevos curadores que utilizan algunas de las características de los curadores tradicionales, pero a partir de propuestas de tipo new age.

Por supuesto que respecto de lo ocurrido, y de nuestras interpretaciones, puede aducirse que 
si bien no se lograron gran parte de los objetivos, se desarrollaron procesos de aprendizaje, que más adelante, sobre todo cuando surjan coyunturas favorables, podrían ser retomados. Lo cual es correcto, pero en la medida en que asumamos que gran parte de los procesos de empoderamiento, autonomía y/o búsqueda de legalidad de la medicina tradicional se dieron, al menos en parte, debido a que las corrientes económico-políticas neoliberales tendieron, durante los años ochenta y noventa, a reconocer e incluso impulsar las "diferencias", los empoderamientos y los emprendimientos, lo cual es reconocido por los movimientos sociales y por sus analistas, ya que además, algunos de ellos plantearon explícitamente el uso de las aporías y aparentes contradicciones del neoliberalismo para, a partir de estas, desarrollar los propios objetivos.

Más aún, por lo menos los intelectuales orgánicos de los movimientos y grupos étnicos sabían no solo del poder técnico, económico y político de la biomedicina, sino de su constante pragmatismo. Una biomedicina que en función de sus objetivos se apropia, permite y/o desecha otras formas de atención en la medida que le permita extender la cobertura o desarrollar vigilancias epidemiológicas para el paludismo o para el $\mathrm{VIH}$-sida, y a las que usa coyuntural y momentáneamente. $Y$, sobre todo, no tomaron en cuenta el constante proceso de penetración, legitimación técnica e ideológica de la biomedicina, no tanto en los curadores tradicionales sino en los sujetos y conjuntos sociales subalternos y no subalternos así como en los gobiernos de, por lo menos, todos los países adheridos a la OMS y a la ONU.

Ahora bien, lo analizado refiere a los procesos de s/e/a-p, y no sabemos hasta qué punto nuestras interpretaciones sobre estos procesos pueden aplicarse a lo que ocurrió y está ocurriendo con los movimientos y organizaciones étnicas en términos políticos, pese a que si bien siguen existiendo organizaciones y luchas en muy diferentes contextos mexicanos, observamos un repliegue de ambas, una expansión continua de las empresas privadas -especialmente las extractivas- sobre los territorios indígenas, un proceso migratorio constante y cada vez menos reversible hacia medios urbanos y/o rurales nacionales y de los EE.UU., así como una profundización de la pobreza, especialmente en las zonas indígenas. Por lo cual considero que lo ocurrido con los procesos de s/e/a-p, por lo menos, problematiza no solo lo que está ocurriendo en términos políticos con los movimientos indígenas en México, sino también las interpretaciones de los analistas, ya que tanto en los procesos de s/e/a-p como en los procesos específicamente políticos observamos similares trayectorias, que sintetizaría en seis aspectos: 1) el repliegue cada vez mayor de las organizaciones étnicas; 2) las limitaciones y fracasos, así como los pocos éxitos en el enfrentamiento y resistencias frente a la expansión de la sociedad dominante; 3) la pérdida de iniciativa y autonomía de los actores subalternos; 4) el aprovechamiento parcial de las contradicciones y problemas de la sociedad dominante; 5) el uso de mecanismos legales que se propusieron a nivel internacional y se establecieron localmente, pero que establecieron expectativas que se cumplieron solo parcialmente; 6) el dominio de la dimensión ideológica tanto en la lectura de los procesos como de las propuestas (s).

Para profundizar lo planteado y analizado en este texto, podría seguir formulando interrogantes respecto de por qué las mujeres, las lesbianas o los gay se organizan en movimientos sociales en torno a sus padecimientos, mientras los varones heterosexuales no; y no solo para establecer algunas conclusiones sobre las posibilidades de organizarse en términos de género, sino de la eficacia diferencial de esta forma de organización (t). O podría plantearme interrogantes respecto de si los grupos y movimientos new age que utilizan concepciones y rituales ancestrales -o supuestamente ancestrales- inciden negativa o positivamente en el desarrollo de los movimientos étnicos, cuyos objetivos son básicamente políticos. O podría analizar cómo a través de lo que pasó en México con la epidemia de influenza A-H1N1 en los años 2009-2010, podemos observar las limitaciones y errores de la descentralización del sector salud mexicano.

Pero considero que, a través de los procesos analizados, ha quedado claro que el análisis de los procesos de s/e/a-p posibilita llegar a detectar, a observar, a problematizar, por lo menos, ciertos aspectos de procesos económico-políticos o ideológico-culturales que no suelen ser considerados por los especialistas en dichos procesos ni por los líderes etnicistas. Del mismo modo, los procesos de s/e/a-p pueden evidenciar no solo las contradicciones y conflictos de los sectores sociales 
dominantes y también de los subalternos, sino poner de manifiesto cuáles son los objetivos, las trayectorias y las transacciones que operan entre los diferentes actores sociales. Así como también permite observar varios de los sesgos, omisiones, e imaginarios que cometemos los analistas de dichos sistemas. En última instancia, lo que estoy concluyendo retoma no solo las propuestas ya citadas de Berlinguer, sino también las de Pierre Bourdieu $(87,88)$, y su obsesión -o tal vez obsesividad-por la problematización y la modificación de la realidad.

\section{NOTAS FINALES}

a. Considero decisivo precisar estos conceptos para entender de qué hablan los analistas cuando se refieren a cosmovisión o subjetividad, dado que la casi totalidad de los autores consultados no los definen o por lo menos no los precisan. Por lo tanto, en este texto nos referimos a cosmovisión, usos y costumbres o identidad tal como lo usan la mayoría de los autores, es decir, en forma "abierta". Aclaro también que, técnicamente, las enfermedades tradicionales son denominadas "síndromes" culturalmente diferenciados por la Organización Mundial de la Salud (OMS), pero en el texto suelo usar como denominación "enfermedades tradicionales".

b. Si bien el referente mayor es América Latina y aun cuando presento datos y reflexiones referidos a otros países de la región, mi análisis se centra en la situación mexicana. Aclaro, además, que la información manejada no solo surge de la bibliografía específica, especialmente para México, sino también de la información que investigadores nacionales y extranjeros han presentado en el Seminario Permanente de Antropología Médica (SEPAM) durante casi treinta años.

c. La mayoría de los estudios sobre síndromes culturalmente delimitados y, en particular, los que tratan sobre cosmovisión y sobre atención de los padecimientos, solo obtienen información de los curadores tradicionales sin incluir los saberes de la población. Esto lo venimos señalando desde nuestro estudio sobre Yucatán (28), lo cual obviamente no niega los aportes y la calidad de muchos de esos trabajos -ver entre otros y para diferentes especialidades: Bartolomé y Barabas (30), Baytelman (31,32), Campos (33), Gallardo (34), Luengas (35), Page (36), Ramos (37), Revista Alteridades (38) - sino que cuestiona reducir la etnografía de los procesos de s/e/a-p, incluidas las cosmovisiones, a los curadores tradicionales, sean parteras empíricas, shamanes o hueseros.

d. Comunicación personal del 25 de agosto de 2011. e. La penetración biomédica debe ser analizada en sí misma, y en relación con otros procesos de tipo social, político y económico, desde las organizaciones políticas desarrolladas por el Partido Revolucionario Institucional (PRI), y por otros partidos políticos para cooptar a sujetos y comunidades indias impulsando cacicazgos, hasta el establecimiento del Ejército Zapatista de Liberación Nacional (EZLN), pasando por el desarrollo de sucesivas organizaciones indígenas con diferentes grados de autonomía; así como la continua expansión de la educación formal, de la aplicación de programas contra la pobreza, y de los procesos migratorios; incluyendo el asentamiento del narcotráfico en tierras indígenas, ya sea en términos de producción de marihuana o amapola, o como control de territorios para la distribución de drogas. Es decir, el análisis de la expansión biomédica implica incluir los diferentes procesos, actores y espacios a través de los cuales se expande la sociedad dominante, que además -y lo subrayo- implica la presencia de procesos de s/e/a-p en la mayoría de dichos espacios. Pero por razones obvias, no podemos desarrollar estos aspectos.

f. Arana y Cabada señalan el incremento del sobrepeso y obesidad en población indígena, y que "Precisamente en estas regiones indígenas es donde se observan las prácticas de mercadeo más agresivas y no reglamentadas para promocionar el consumo de bebidas azucaradas, incluyendo una reducción generalizada de $35 \%$ del precio de las mismas, abundante publicidad en español y en lenguas indígenas, gigantes anuncios que asocian el consumo de refrescos con símbolos tradicionales de prestigio, así como numerosos puntos de venta dentro y en los alrededores de las escuelas" (39). Estos autores, en la región de Tenejapa (Altos de Chiapas), identificaron 165 puntos de venta de refrescos en una distancia de 42,5 kilómetros, es decir que hay un punto de venta cada 257,5 metros. Ver también Page (40).

g. Aclaro que el reconocimiento de los aportes de la biomedicina no solo clínica sino salubrista lo hacemos a partir de asumir los aspectos negativos, tal como lo venimos describiendo y analizando desde 
finales de la década de 1960 a través del Modelo Médico Hegemónico (4,5,13,19,28,29,41,42).

h. "Para Félix Durán Quispe (2006), el médico tradicional no solo es el hombre llamado a curar los síntomas de las enfermedades, sino a establecer la armonía primordial del cosmos con su realidad comunitaria. Para él la medicina tradicional utiliza métodos bajo el principio de humanidad..." (50 p.35). Para observar una concepción similar en los shamanes y otros curadores tradicionales mexicanos ver Bartolomé y Barabas (30).

i. Entre 2000 y 2014 antropólogos sociales que trabajan en áreas indígenas de Chiapas, Chihuahua, Guerrero, Oaxaca, Sonora y Yucatán me informaron no solo de la disminución de curadores tradicionales, sino de que los jóvenes no querían ya trabajar como curadores populares, aunque sí como promotores. Incluso en una comunidad de Oaxaca y en otra de Guerrero, curadores tradicionales les preguntaron a sendos antropólogos qué podían hacer para que los jóvenes se interesaran por actuar como curadores tradicionales.

j. Cuadrillero y Megchún (54) describen la trayectoria de una mujer tzeltal residente en las Cañadas de la Selva Lacandona que padecía un fuerte dolor de espalda y que acudió a promotores de salud locales, a la clínica regional, al hospital de cabecera municipal, al huesero de dicha cabecera, a una curandera de fuera de su comunidad. Esta trayectoria supone varios tipos de curadores biomédicos y "tradicionales", y procesos similares podemos observar en muy diferentes contextos rurales y urbanos, originarios y mestizos $(29,51,55-57)$.

k. EI BRICS está integrado por Brasil, Rusia, India, China y Sudáfrica.

I. La medicina "occidental" tiene sus principales raíces no solo en Grecia, Roma y Europa medieval y renacentista, sino también en China, India y países árabes (71).

m. Es posible que también hayan muerto curadores tradicionales, pero es casi seguro que oponiéndose a las medidas biomédicas en función de dos hechos: primero, porque algunas de dichas medidas afectaban fuertemente los rituales mortuorios tradicionales y, segundo, porque las acciones biomédicas eran impulsadas por gobiernos no solo caracterizados por la corrupción, sino por la explotación, lo que dio lugar al desarrollo y difusión de ideas que evidencian la gran desconfianza que la población tiene respecto de las autoridades políticas, ya que algunos rumores consideraban que el Ébola era un problema inventado por los gobiernos para seguir recaudando fondos $y$, por lo tanto, el personal de salud era considerado un agente que actuaba simultáneamente contra las costumbres mortuorias y contra la economía de las comunidades. Es decir que los procesos de s/e/a-p pueden expresar tanto los conflictos de los sistemas, como las acciones sociopolíticas que los sujetos y grupos crean para "resolver" dichos conflictos, y que pueden parecernos paradojales o incomprensibles si no tenemos la información suficiente para entender no solo las lógicas culturales, sino también las económicas.

n. La elección de Cuba no solo es por razones de tipo ideológico, sino también económico, dado el bajo costo de los estudios universitarios comparado con el de sus países de origen.

o. En el estado mexicano de Guerrero se esterilizó a varones de origen indígena con el consentimiento de ellos, lo que produjo que se movilizaran debido a que el sector salud no les dio el dinero que les había prometido si aceptaban ser esterilizados (4).

p. Bolivia es el país con mayor porcentaje de población indígena como ya se señaló, y que tiene la población que más atiende los partos por autoatención y/o con parteras empíricas, pero también el país con mayor porcentaje de muertes maternas después de Haití (85). Obviamente, las altas tasas de mortalidad materna no solo se deben a los dos "factores" señalados, aunque son determinantes.

q. Ello no ignora la eficacia simbólica y no simbólica observada en el trabajo de hueseros, parteras, curanderos o brujos, pero no tiene capacidad para enfrentar y reducir la mortalidad por problemas cardiovasculares, cancerígenos, por VIH-sida, o por las Ilamadas muertes "evitables" generadas por enfermedades infectocontagiosas, o incluso las benignas.

r. Para una discusión de los conceptos tradicional y medicina tradicional ver "La enfermedad y la curación: ¿Qué es medicina tradicional? (86).

s. No desconozco el papel de las violencias legales e ilegales, así como los procesos de cooptación política en los procesos señalados, que si bien pueden ser decisivos para los objetivos políticos de los movimientos, no han tenido un papel relevante en la trayectoria de los procesos de s/e/a-p analizados.

t. Si bien Alcohólicos Anónimos fue creado e impulsado por varones, no obstante constituye un grupo de autoayuda que por sus objetivos y dinámica no puede ser considerado un movimiento social. 


\section{REFERENCIAS BIBLIOGRÁFICAS}

1. Berlinguer G. La reforma sanitaria en Italia. Sinaloa: Universidad Autónoma de Sinaloa; 1983.

2. Berlinguer G. Medicina y política. México: Quinto Sol; 2006.

3. Menéndez EL. La parte negada de la cultura: Relativismo, diferencias y racismo. Barcelona: BeIlaterra; 2002.

4. Menéndez EL. De sujetos, saberes y estructuras: Introducción al enfoque relacional en el estudio de la salud colectiva. Buenos Aires: Lugar Editorial; 2009.

5. Menéndez EL. De racismos, esterilizaciones y algunos otros olvidos de la antropología y de la epidemiología mexicanas. Salud Colectiva. 2009;5(2):155-179.

6. Harrington M. The Other America: Poverty in the United States. New York: Macmillan; 1962.

7. Kolko G. Wealth and Power in the United States. New York: Frederick Praeger; 1962.

8. Riesman F, Cohen J, Pearl A. Mental health of the poor. New York: The Free Press; 1964.

9. Hertzman C, Siddiqi A. Health and rapid economic change in the late twentieth century. Social Science \& Medicine. 2000;35(11):1369-1378.

10. Leon DA, Chenet L, Shkolnikov VM, Zakharov S, Shapiro J, Rakhmanova G, Vassin S, McKee M. Huge variations in Russian mortality rates 1984/1994: artifact, alcohol or what? The Lancet. 1997;350:383-388.

11. Guibert W. Epidemiología de la conducta suicida. Revista Cubana de Medicina General Integral. 2002;18:1-7.

12. Hagedus A. Socialismo y burocracia. Barcelona: Ediciones Península; 1978.

13. Menéndez EL. Cura y control: La apropiación de lo social por la práctica psiquiátrica. México: Editorial Nueva Imagen; 1979.

14. Perez Jr. LA. To die in Cuba: Suicide and society. The University of North Carolina Press; 2005

15. Fort M, Mercer MA, Gish O. El negocio de la salud: Los intereses de las multinacionales y la privatización de un bien público. Barcelona: Paidos Ibérica; 2006.
16. La Rosa E. La fabricación de patologías. Lima: Fondo de Cultura Económica; 2009.

17. Moynihan R, Cassels A. Medicamentos que enferman e industrias farmaceúticas que nos convierten en pacientes. Buenos Aires: Editorial Atlántida; 2006.

18. Astorga L. Drogas sin frontera: los expedientes de una guerra permanente. México: Grijalbo; 2003.

19. Menéndez EL. Morir de alcohol: Saber y hegemonía médica. México: Alianza Editorial; 1990.

20. Menéndez EL. ¿Qué drogas matan más? Algunos comentarios sobre las políticas prohibicionistas aplicadas a las sustancias consideradas adictivas. Ichan tecolotl. 2012;(266):3-6.

21. Romaní O. Las drogas: Sueños y razones. Barcelona: Ariel; 1999.

22. Valdés G. Historia del narcotráfico en México. México: Editorial Aguilar; 2013.

23. McKeown T. The modern rise of population. London: Academic Press; 1976.

24. McKeown T. Los orígenes de las enfermedades humanas. Barcelona: Crítica; 1990.

25. Kentikelenis A, King L, McKee M, Stuckle D. The International Monetary Fund and the Ebola outbreak. The Lancet Global Health. 2014;3(2):e69.

26. Médicos sin Fronteras. Ébola en 2014: La vergonzosa respuesta internacional ha costado la vida a miles de personas [Internet]. 2 ene 2015 [citado 15 ene 2015]. Disponible en: https://goo. $\mathrm{gl} / \mathrm{IOHpzc}$

27. Baud M, Koonings K, Oostindie G, Ouweneel A, Silva P. Etnicidad como estrategia en América Latina y el Caribe. Quito: Abya-Yala; 1996.

28. Menéndez EL. Poder, estratificación y salud: Análisis de las condiciones sociales y económicas de la enfermedad en Yucatán. México: Ediciones de la Casa Chata; 1981.

29. Menéndez EL. Antropología Médica: Orientaciones, desigualdades y transacciones. México DF: CIESAS; 1990. (Cuadernos de la Casa Chata 179)

30. Bartolomé MA, Barabas AM, compiladores. Los sueños y los días: Chamanismo y nahualismo en el México actual. México DF: Instituto Nacional de Antropología e Historia; 2013. 
31. Baytelman B. De enfermos y curanderos, medicina tradicional en Morelos. México DF: INAH; 1986.

32. Baytelman B. Acerca de las plantas y curanderos. México DF: INAH; 1993.

33. Campos R. Nosotros los curanderos. México DF: Nueva Imagen; 1990.

34. Gallardo J. Medicina tradicional p'urhépecha. Zamora: El Colegio de Michoacán; 2002.

35. Luengas MI. El saber y el quehacer de las parteras en el medio rural mexicano [Tesis de Maestría]. México DF: Facultad de Ciencias Políticas y Sociales, Universidad Nacional Autónoma de México; 1994.

36. Page-Pliego JT. El Mandato de los dioses: Etnomedicina entre los tzotziles de Chamula y Chenalhó, Chiapas. San Cristóbal de las Casas: UNAM; 2005.

37. Ramos I. Hueseros y sobadores en la ciudad de México: Un estudio de caso [Tesis de Maestría]. México DF: Posgrado en Antropología Social, Escuela Nacional de Antropología e Historia; 2002.

38. Antropología de la curación. Revista Alteridades [Internet]. 1996;(12) [citado 12 ene 2015]. Disponible en: http://goo.gl/Foo9Yn.

39. Arana Cedeño M, Cabada X. La amarga realidad del azúcar: mayores riesgos y amenazas para los pueblos indígenas en México. En: Observatorio del Derecho a la Alimentación y a la Nutrición. ¿Quién decide sobre la alimentación y nutrición a nivel global? Reinheim: Brot für die Welt, FIAN Internacional, ICCO; 2012. p. 46-48.

40. Page-Pliego JT. Refresco y diabetes entre los mayas de Tenejapa, San Cristóbal y Chamula, Chiapas. LiminaR: Estudios Sociales y Humanísticos. 2013;11(1):118-133.

41. Menéndez EL. Políticas del Sector Salud mexicano (1980-2004): ajuste estructural y pragmatismo de las propuestas neoliberales. Salud Colectiva. 2005; 1(2):195-224.

42. Menéndez EL. Poblaciones abiertas, seguras y privadas: cambios, reorientaciones y permanencias en el sector salud mexicano. En: Asis A, Alonso J, coordinadores. El estado mexicano: herencias y cambios. México DF: Porrúa/CIESAS; 2005. vol II; p.151-192.

43. Menéndez EL, editor. Antropología del alcoholismo en México: Los límites culturales de la economía política, 1930-1979. México: Ediciones de la Casa Chata; 1991.

44. Guiteras C. Los peligros del alma: Visión del mundo de un tzotzil. México: Fondo de Cultura Económica; 1965.

45. Pitarch P. Ch'ulel: una etnografía de las almas tzeltales. México: Fondo de Cultura Económica; 1996.

46. Instituto Nacional de Estadística y Geografía. Encuesta Nacional de la Dinámica Demográfica 2009 [Internet]. 2010 [citado 10 ene 2013]. Disponible en: http://goo.gl/3rqYoJ.

47. Berrio L. Entre la normatividad comunitaria y las instituciones de salud: Procesos reproductivos y salud materna en mujeres indígenas de la Costa chica de Guerrero [Tesis de Doctorado]. División de Ciencias Sociales y Humanas, Universidad Autónoma Metropolitana-Unidad Iztapalapa; 2013.

48. Berrio L. Trayectorias reproductivas y prácticas de atención a la salud meterna entre mujeres indígenas de la Costa Chica de Guerrero. En: Sánchez Bringas A, coordinador. Desigualdades en la procreación: Trayectorias reproductivas, atención obstétrica y morbimortalidad materna en México. México: UAM: 2014. p. 211-243.

49. Observatorio de Mortalidad Materna. La muerte materna tiene rostro: Indicadores [Internet]. México DF: OMM; 2010 [citado 12 ene 2015]. Disponible en: http://goo.gl/x6ed7n.

50. Organización Panamericana de la Salud. Una visión de salud intercultural para los pueblos indígenas de las Américas [Internet]. Washington DC: OPS; 2008 [citado 12 ene 2015]. Disponible en: http://goo.gl/ctZhLb.

51. Ortega J. Proceso reproductivo femenino: saberes, género y generaciones en una comunidad maya de Yucatán [Tesis de Doctorado]. El Colegio de Michoacán; 1999.

52. Page-Pliego JT. Política sanitaria dirigida a los pueblos indígenas de México y Chiapas 1857-1995. Chiapas: UNACH, IEI, UNAM; 2002.

53. Freyermuth-Enciso G. Médicos tradicionales y médicos alópatas: Un encuentro difícil en los Altos de Chiapas. Tuxtla Gutiérrez: Gobierno del Estado de Chiapas, CIESAS; 1993.

54. Cuadriello OH, Megchún Rivera R. El desplazamiento de curadores y brujos entre los tzeltales de las Cañadas de la Selva Lacandona. En: Bartolomé MA, Barabas AM, coords. Los sueños y los días: Chamanismo y nahualismo en el México 
actual. México DF: Instituto Nacional de Antropología e Historia; 2013. vol II; p. 213-228.

55. Mendoza Z. De lo biomédico a lo popular: El proceso de salud/enfermedad/atención en San Juan Copala, Oaxaca [Tesis de Maestría]. México DF: Posgrado en Antropología Social, Escuela Nacional de Antropología e Historia; 1994.

56. Osorio RM. La cultura médica materna y la salud infantil [Tesis de Maestría]. México DF: Posgrado en Antropología Social, Escuela Nacional de Antropología e Historia; 1994.

57. Press I. Tradition and adaptation: Life in a modern Yucatan Maya Village. Connecticut: Greenwood Press; 1975.

58. Aguirre Beltrán G. Programa de salud en la situación intercultural. México DF: Fondo de Cultura Económica; 1994.

59. Meneses S. Semiótica de la otredad, la diferencia como diagnosis: Etnografía de los encuentros médicos interétnicos en los Altos de Chiapas [Tesis de Maestría]. México DF: Maestría en Antropología Social, CIESAS; 2005.

60. Erasmus C. El hombre asume el control. Buenos Aires: Omeba; 1963.

61. Araya MJ. Parteras indígenas: Los conocimientos tradicionales frente al genocidio neoliberal. Quito: Abya-Yala; 2011.

62. Alarcón-Lavín RR. La biopiratería de los recursos de la medicina tradicional en el estado de Chiapas, México: El caso ICBG-Maya. Revista Pueblos y Fronteras Digital [Internet]. 2010 [citado 12 ene 2015];6(10). Disponible en: http://goo.gl/ UDTASt.

63. Castro Soto J. Pukuj: Biopiratería en Chiapas. San Cristóbal de las Casas: CIEPAC; 2000.

64. Warman A. Los indios mexicanos en el umbral del milenio. México DF: Fondo de Cultura Económica; 2003.

65. Freyermuth G. La mortalidad materna y los nudos en la prestación de los servicios de salud en Chiapas: Un análisis desde la interculturalidad. LiminaR. 2014;XII(2):30-45.

66. Berrio L. ¿Cuidar la salud o modificar realidades?: El papel de la biomedicina en las prácticas de atención durante el embarazo y parto en la Costa Chica de Guerrero. México DF: Seminario Permanente de Antropología Médica, CIESAS; 2015.
67. Baronet B, Mora Bayo M, Stahler-Sholk R, coords. Luchas "muy otras": Zapatismo y autonomía en las comunidades indígenas de Chiapas. México DF: UAM-Xochimilco; 2012.

68. Cerda A. Imaginando zapatismo: Multiculturalidad y autonomía indígena en Chiapas desde un municipio autónomo. México DF: UAM-Xochimilco; 2011.

69. Zolla C, Sánchez C. Pueblos indígenas e indicadores de salud. México DF: UNAM; 2010.

70. Knipper M. El reto de la "medicina intercultural" y la historia de la "medicina tradicional" indígena contemporánea. En: Fernández Juárez G, coord. Salud e interculturalidad en América Latina: Antropología de la salud y crítica intercultural. Quito: Abya-Yala; 2006. p. 413-432.

71. Huff T. The rise of early modern science: Islam, China and the West. Cambridge: Cambridge University Press; 1993.

72. Agence France-Presse. Van 7 mil 708 víctimas mortales a causa del ébola. La Jornada [Internet]. 27 dic 2014 [citado 12 ene 2015]. Disponible en: http://goo.gl/ADUpff.

73. Quintal F, Briceño F, Cabrera A. Los que hablan con los vientos: los jmeeno'ob. En: Bartolomé MA, Barabas AM, coords. Los sueños y los días: Chamanismo y nahualismo en el México actual. México DF: Instituto Nacional de Antropología e Historia; 2013. vol II, p. 145-198.

74. Halperin D, et al. Contracepción, percepciones y prácticas de anticoncepción en el estado de Chiapas. En: Glantz Wright NM, Martínez Hernández I, León Ruíz P. Diez años de investigación y acción en el sur de Chiapas. Comitán, Chiapas: Centro de Investigación en Salud de Comitán; 1999. p. 135-165.

75. Fernández Juárez G. "AI hospital van los que mueren": Desencuentros en salud intercultural en los Andes bolivianos. En: Fernández Juárez G, coord. Salud e interculturalidad en América Latina: antropología de la salud y crítica intercultural. Ciudad Real: Universidad de Castilla-La Mancha; 2006. p. 317-336.

76. Ramírez-Hita S. Salud intercultural: Crítica y problematización a partir del contexto boliviano. La Paz: SEAT; 2011.

77. Callahan M. El hospital Kallawaya "Hoquena Husi" de Curva: Un experimento en salud intercultural. En: Fernández Juárez G, coord. Salud e interculturalidad en América Latina: antropología de la salud y crítica intercultural. Ciudad Real: 
Universidad de Castilla-La Mancha; 2006. p. 289-303.

78. Ramírez-Hita S. Aspectos interculturales de la reforma del sistema de salud en Bolivia. Revista Peruana de Medicina Experimental y Salud Pública. 2014;31(4):762-768.

79. Reinaga F. La podredumbre criminal del pensamiento europeo. La Paz: Ediciones Comunidad Amaútica Mundial; 1982.

80. Baschet J. Los zapatistas: ¿ “Ventiloquia india” o interacciones creativas? Istor. 2005;(22):110-128.

81. Pitarch P. Los Zapatistas y el arte de la ventriloquia. Istor. 2004;(17):95-132.

82. Pitarch P. "Ventriloquia confusa". Istor. 2005; (22):129-144.

83. Sánchez-Escobedo $P$, Cetina-Canto T, Menéndez-Antuñano P. Efectos psicológicos de la esterilización quirúrgica en mujeres yucatecas [Internet]. 1994 [citado 10 ene 2015]. Disponible en: http:// goo.gl/dnlTfp.
84. Menéndez EL, Di Pardo RB. Sector Salud y organizaciones no-gubernamentales: convergencias y articulaciones en torno a la salud reproductiva. AM-Rivista della Società Italiana di Antropologia Medica. 2010-2011;29-32:215-252.

85. Uribe G. Mortalidad materna en Bolivia: ¿Qué hacer para evitar tantas muertes de mujeres? En: Fernández Juárez G, coord. Salud e interculturalidad en América Latina: antropología de la salud y crítica intercultural. Ciudad Real: Universidad de Castilla-La Mancha; 2006. p. 173-186.

86. Menéndez EL. La enfermedad y la curación: ¿Qué es medicina tradicional? Alteridades. 1994;(7):71-83.

87. Bourdieu P. Contrafuegos: reflexiones para servir a la resistencia contra la invasión neoliberal. Barcelona: Anagrama; 1999.

88. Bourdieu P, Chamboredon JC, Passeron JC. El oficio de sociólogo: Presupuestos epistemológicos. México DF: Siglo XXI Editores; 1975.

\section{FORMA DE CITAR}

Menéndez EL. Las enfermedades ison solo padecimientos?: biomedicina, formas de atención "paralelas" y proyectos de poder. Salud Colectiva. 2015;11(3):301-330.

Recibido: 16 de febrero de 2015 | Aprobado: 23 de abril de 2015

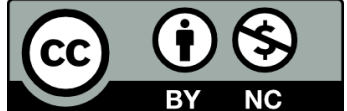

Este obra está bajo una licencia de Creative Commons Reconocimiento-NoComercial 4.0 Internacional. Reconocimiento - Permite copiar, distribuir y comunicar públicamente la obra. A cambio, se debe reconocer y citar al autor original. No Comercial - Esta obra no puede ser utilizada con finalidades comerciales, a menos que se obtenga el permiso.

http://dx.doi.org/10.18294/sc.2015.719 